Acta Crystallographica Section B

Structural

Science

ISSN 0108-7681
David E. Turkington, ${ }^{\mathrm{a}}$ Alan J. Lough, $^{\mathrm{b}}$ George Ferguson ${ }^{\mathrm{a}, \mathrm{c}}$ and Christopher Glidewell ${ }^{\mathrm{a} *}$

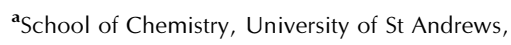
St Andrews, Fife KY16 9ST, Scotland, 'bash Miller Chemical Laboratories, University of Toronto, Toronto, Ontario, Canada M5S 3H6, and ${ }^{\mathrm{c}}$ Department of Chemistry, University of Guelph, Guelph, Ontario, Canada N1G 2W1

Correspondence e-mail: cg@st-andrews.ac.uk

\section{Hydrogen-bonded adducts of triphenylsilanol with diamines: a finite ten-molecule aggregate, and chain, sheet and framework structures built from $\mathrm{O}-\mathrm{H} \cdots \mathrm{O}, \mathrm{O}-\mathrm{H} \cdots \mathrm{N}$ and $\mathrm{C}-\mathrm{H} \cdots \pi$ (arene) hydrogen bonds}

The structures of five hydrogen-bonded adducts of triphenylsilanol, $\mathrm{Ph}_{3} \mathrm{SiOH}$, with diamines have been determined. In the Received 22 January 2004 4:1 adduct formed with 1,4-diazabicyclo[2.2.2]octane, $\left(\mathrm{Ph}_{3} \mathrm{SiOH}\right)_{4} \cdot \mathrm{C}_{6} \mathrm{H}_{12} \mathrm{~N}_{2}$ (I) (triclinic, $P \overline{1}, Z^{\prime}=2$ ), there are two independent five-component aggregates built from $\mathrm{O}-\mathrm{H} \cdots \mathrm{N}$ and $\mathrm{O}-\mathrm{H} \cdots \mathrm{O}$ hydrogen bonds, in one of which the diamine exhibits orientational disorder: these two aggregates are linked into a cyclic ten-molecule unit by means of two independent $\mathrm{C}-\mathrm{H} \cdots \pi$ (arene) hydrogen bonds. The 4:1 adduct formed with 1,2-bis(4-pyridyl)ethene, $\left(\mathrm{Ph}_{3} \mathrm{SiOH}\right)_{4} \cdot \mathrm{C}_{12} \mathrm{H}_{10} \mathrm{~N}_{2}$ (II) (triclinic, $P \overline{1}, Z^{\prime}=0.5$ ), forms a similar five-component aggregate which lies across a centre of inversion: a single $\mathrm{C}-\mathrm{H} \cdots \pi$ (arene) hydrogen bond links these aggregates into a molecular ladder. With $N, N^{\prime}$ dimethylpiperazine, triphenylsilanol forms a 2:1 adduct, $\left(\mathrm{Ph}_{3} \mathrm{SiOH}\right)_{2} \cdot \mathrm{C}_{6} \mathrm{H}_{14} \mathrm{~N}_{2}$ (III) (monoclinic, $P 2_{1} / c, Z^{\prime}=0.5$ ), in which a three-component aggregate built from $\mathrm{O}-\mathrm{H} \cdots \mathrm{N}$ hydrogen bonds lies across a centre of inversion: two independent $\mathrm{C}-\mathrm{H} \cdots \pi$ (arene) hydrogen bonds link these aggregates into sheets. In the hydrated 2:1 adduct formed with 1,2-bis(4'-bipyridyl)ethane, $\left(\mathrm{Ph}_{3} \mathrm{SiOH}\right)_{2} \cdot \mathrm{C}_{12} \mathrm{H}_{12} \mathrm{~N}_{2} \cdot \mathrm{H}_{2} \mathrm{O}$ (IV) (triclinic, $P 1, Z^{\prime}=1$ ), a combination of two independent $\mathrm{O}-$ $\mathrm{H}$. . O and two independent $\mathrm{N}-\mathrm{H}$. . O hydrogen bonds links the five molecular components into a centrosymmetric eightmolecule aggregate, and six independent $\mathrm{C}-\mathrm{H} \cdots \pi$ (arene) hydrogen bonds link these chains into a continuous threedimensional framework structure. In the dihydrated 2:1 adduct formed with 4,4'-bipyridyl, $\left(\mathrm{Ph}_{3} \mathrm{SiOH}\right)_{2} \cdot \mathrm{C}_{10} \mathrm{H}_{8} \mathrm{~N}_{2} \cdot\left(\mathrm{H}_{2} \mathrm{O}\right)_{2}(\mathrm{~V})$ (triclinic, $P \overline{1}, Z^{\prime}=1$ ), a combination of four independent $\mathrm{O}-\mathrm{H} \cdots \mathrm{O}$ and two independent $\mathrm{N}-\mathrm{H} \cdots \mathrm{O}$ hydrogen bonds links the five molecular components into a chain of rings, and four independent $\mathrm{C}-\mathrm{H} \cdots \pi$ (arene) hydrogen bonds link these chains into a continuous three-dimensional framework structure.

\section{Introduction}

We have recently observed that co-crystallization, from methanol solutions, of mixtures of triphenylsilanol, $\mathrm{Ph}_{3} \mathrm{SiOH}$ [A, see Scheme (I)], and 4,4'-bipyridyl, $\mathrm{NC}_{5} \mathrm{H}_{4}-\mathrm{C}_{5} \mathrm{H}_{4} \mathrm{~N}(B)$, gave a 1:1 adduct $\mathrm{Ph}_{3} \mathrm{SiOH} \cdot \mathrm{C}_{10} \mathrm{H}_{8} \mathrm{~N}_{2}$, in which the two molecular components are linked by an $\mathrm{O}-\mathrm{H} \cdot \mathrm{N}$ hydrogen bond, and a 4:1 adduct $\left(\mathrm{Ph}_{3} \mathrm{SiOH}\right)_{4} \cdot \mathrm{C}_{10} \mathrm{H}_{8} \mathrm{~N}_{2}$ (Bowes et al., 2003). In the $4: 1$ adduct, two triphenylsilanol molecules are linked to the 4,4'-bipyridyl via $\mathrm{O}-\mathrm{H} \cdots \mathrm{N}$ hydrogen bonds and two further triphenylsilanol molecules are linked to the first pair via $\mathrm{O}-$ 
$\mathrm{H}$... O hydrogen bonds. However, it did not prove possible to isolate or identify the expected 2:1 adduct, $\left(\mathrm{Ph}_{3} \mathrm{SiOH}\right)_{2} \cdot \mathrm{C}_{10} \mathrm{H}_{8} \mathrm{~N}_{2}$, containing $\mathrm{O}-\mathrm{H} \cdots \mathrm{N}$ but not $\mathrm{O}-$ $\mathrm{H}$... O hydrogen bonds. Moreover, three different polymorphs of the 4:1 adduct were characterized, all in the triclinic space group $P \overline{1}$ and having $Z^{\prime}$ values of $0.5,1$ and 4 , respectively. These polymorphs, which are at least pairwise concomitant, all exhibit considerable disorder, even at $150 \mathrm{~K}$, particularly involving the orientation of the phenyl rings. By contrast, the 1:1 adduct has a fully ordered structure in which the bimolecular aggregates generated by the $\mathrm{O}-\mathrm{H} \cdots \mathrm{N}$ hydrogen bond are linked into a continuous three-dimensional framework structure by no fewer than four different $\mathrm{C}-\mathrm{H} \cdots \pi$ (arene) hydrogen bonds involving both phenyl and pyridyl rings as acceptors.

Intrigued by the crystallization behaviour of this system, giving 1:1 and 4:1 adducts but no 2:1 adduct, as well as by the polymorphism of the $4: 1$ adduct, we have now investigated the co-crystallization of a range of mixtures containing triphenylsilanol and other diamines, including 1,2-bis(4-pyridyl)ethene $\quad(C), \quad$ 1,2-bis(4-pyridyl)ethane $\quad(D), \quad$ 1,4diazabicyclo[2.2.2] octane (DABCO, E), $N, N^{\prime}$-dimethylpiperazine $(F)$, piperazine $(G)$ and hexamethylenetetramine $(H)$.

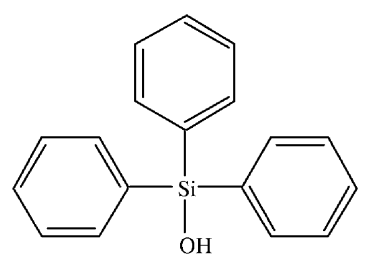

(A)

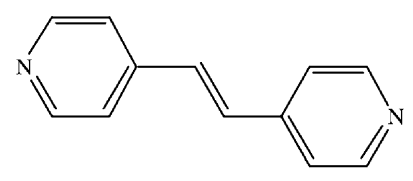

(C)

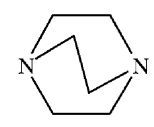

(E)

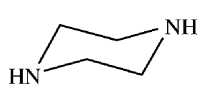

(G)

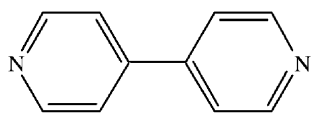

(B)

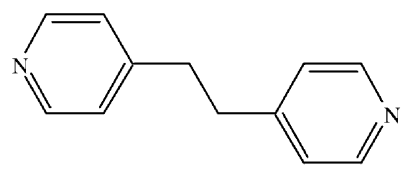

(D)

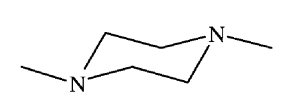

(F)

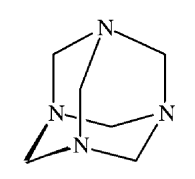

(H)
(I)

In the cases of diamines $(C)$ and $(E)$, methanol solutions containing triphenylsilanol and the diamine in molar ratios of $1: 1,2: 1$ or $4: 1$ (triphenylsilanol:diamine in all cases) uniformly yielded the 4:1 adducts (I) and (II) only as the sole crystalline products. In contrast, diamine $(F)$ produced only the 2:1 adduct (III), whereas diamine $(D)$ produces the monohydrated 2:1 adduct (IV). Use of the amines $(G)$ and $(H)$ consistently failed to produce any crystalline adducts and triphenylsilanol was the only solid product isolated from crystallizations involving these amines. In addition, we have now isolated and characterized a further product in the triphenylsilanol-4,4'-bipyridyl system, namely the hydrated 2:1 adduct $\left(\mathrm{Ph}_{3} \mathrm{SiOH}\right)_{2} \cdot \mathrm{C}_{10} \mathrm{H}_{8} \mathrm{~N}_{2} \cdot\left(\mathrm{H}_{2} \mathrm{O}\right)_{2}(\mathrm{~V})$.

\section{Experimental}

\subsection{Synthesis}

For each of compounds (I)-(IV), stoichiometric quantities of triphenylsilanol and the diamines $(E),(C),(F)$ or $(D)$, respectively, equivalent to 1:1, 2:1 and 4:1 molar ratios in each case, were separately dissolved in dry methanol. The corresponding solutions were mixed and set aside to crystallize, consistently providing samples of (I)-(IV). Analyses: found for (I), C 76.9, $\mathrm{H} 6.5, \mathrm{~N} 2.2 \% ; \mathrm{C}_{78} \mathrm{H}_{76} \mathrm{~N}_{2} \mathrm{O}_{4} \mathrm{Si}_{4}$ requires C 76.9, $\mathrm{H}$ 6.3, N 2.3\%; found for (II), C 78.6, $\mathrm{H}$ 5.4, N 2.1\%; $\mathrm{C}_{84} \mathrm{H}_{74} \mathrm{~N}_{2} \mathrm{O}_{4} \mathrm{Si}_{4}$ requires C 78.3, H 5.8, N 2.2\%; found for (III), C 76.2, H 6.9, N 3.9\%; $\mathrm{C}_{42} \mathrm{H}_{46} \mathrm{~N}_{2} \mathrm{O}_{2} \mathrm{Si}_{2}$ requires C 75.6, H 7.0, N $4.2 \%$; found for (IV) C 75.8, H 6.0, N 3.3\%; $\mathrm{C}_{48} \mathrm{H}_{46} \mathrm{~N}_{2} \mathrm{O}_{3} \mathrm{Si}_{2}$ requires $\mathrm{C} 76.3, \mathrm{H} 6.1, \mathrm{~N} 3.7 \%$. For (V) equimolar quantities of triphenylsilanol and 4,4'-bipyridyl were employed in a similar co-crystallization. Analysis for (V): found $\mathrm{C} 75.3, \mathrm{H}$ 5.7, N $3.7 \% ; \mathrm{C}_{46} \mathrm{H}_{44} \mathrm{~N}_{2} \mathrm{O}_{4} \mathrm{Si}_{2}$ requires $\mathrm{C} 74.2, \mathrm{H} 6.0, \mathrm{~N} 3.8 \%$. When piperazine $(G)$ or hexamethylenetetramine $(H)$ were employed in similar co-crystallization experiments, the crystallized products were consistently found to be pure triphenylsilanol. Crystals of (I)-(V) suitable for single-crystal X-ray diffraction were selected directly from the analytical samples.

\subsection{Data collection, structure solution and refinement}

Diffraction data for (I)-(V) were collected at 150 (1) K using a Nonius Kappa-CCD diffractometer with graphitemonochromated Mo $K \alpha$ radiation $(\lambda=0.71073 \AA)$. Other details of cell data, data collection and refinement are summarized in Table 1, together with details of the software employed. Compounds (I), (II), (IV) and (V) are all triclinic, and for each of them the space group $P \overline{1}$ was selected and confirmed by the successful structure analyses: for (III) the space group $P 2_{1} / c$ was uniquely assigned from the systematic absences. The structures were solved by direct methods and refined with all data on $F^{2}$. A weighting scheme based upon $P=\left[F_{o}^{2}+2 F_{c}^{2}\right] / 3$ was employed in order to reduce statistical bias (Wilson, 1976). All $\mathrm{H}$ atoms were located from difference maps and all were fully ordered. Those bonded to water $\mathrm{O}$ atoms were placed at positions located from the difference maps and treated as riding atoms with an $\mathrm{O}-\mathrm{H}$ distance of $0.99 \AA$, as deduced from the difference maps; all other $\mathrm{H}$ atoms were treated as riding atoms with distances $\mathrm{C}-\mathrm{H}$ $0.95 \AA$ and hydroxy $\mathrm{O}-\mathrm{H} 0.84 \AA$. In (I) one of the DABCO components, that containing $\mathrm{N} 21$ and $\mathrm{N} 22$, is disordered over 
Table 1

Experimental details.

\begin{tabular}{|c|c|c|c|c|c|}
\hline & (I) & (II) & (III) & (IV) & $(\mathrm{V})$ \\
\hline \multicolumn{6}{|l|}{ Crystal data } \\
\hline Chemical formula & $\begin{array}{l}\mathrm{C}_{6} \mathrm{H}_{12} \mathrm{~N}_{2} \cdot- \\
\quad 4 \mathrm{C}_{18} \mathrm{H}_{16} \mathrm{OSi}\end{array}$ & $\begin{array}{l}2 \mathrm{C}_{18} \mathrm{H}_{16} \mathrm{OSi} \cdot- \\
\quad 0.5 \mathrm{C}_{12} \mathrm{H}_{10} \mathrm{~N}_{2}\end{array}$ & $\begin{array}{l}\mathrm{C}_{18} \mathrm{H}_{16} \mathrm{OSi} \cdot- \\
0.5 \mathrm{C}_{6} \mathrm{H}_{14} \mathrm{~N}_{2}\end{array}$ & $\begin{array}{l}2 \mathrm{C}_{18} \mathrm{H}_{16} \mathrm{OSi} \cdot- \\
\mathrm{C}_{12} \mathrm{H}_{12} \mathrm{~N}_{2} \cdot \mathrm{H}_{2} \mathrm{O}\end{array}$ & $\begin{array}{l}2 \mathrm{C}_{18} \mathrm{H}_{16} \mathrm{OSi} \\
\quad \mathrm{C}_{10} \mathrm{H}_{8} \mathrm{~N}_{2} \cdot 2 \mathrm{H}_{2} \mathrm{O}\end{array}$ \\
\hline$M_{r}$ & 1217.77 & 643.91 & 333.49 & 755.05 & 745.01 \\
\hline $\begin{array}{l}\text { Cell setting, } \\
\text { space group }\end{array}$ & Triclinic, $P \overline{1}$ & Triclinic, $P \overline{1}$ & Monoclinic, $P 2_{1} / c$ & Triclinic, $P \overline{1}$ & Triclinic, $P \overline{1}$ \\
\hline$a, b, c(\AA)$ & $\begin{array}{l}15.2124(5), 18.9580(4), \\
23.3561(7)\end{array}$ & $\begin{array}{l}8.6418(2), 14.1263(3) \\
16.3149(4)\end{array}$ & $\begin{array}{l}14.6528(10), 8.1361(4) \\
16.7852(10)\end{array}$ & $\begin{array}{l}8.7793(4), 14.3503(7) \\
\quad 16.8948(6)\end{array}$ & $\begin{array}{l}8.9058(4), 13.9098(8), \\
16.9083(8)\end{array}$ \\
\hline$\alpha, \beta, \gamma\left(^{\circ}\right)$ & $\begin{array}{l}86.713(2), 85.727(2), \\
81.563(2)\end{array}$ & $\begin{array}{l}64.5048(10), 84.1339 \\
\quad(10), \\
79.7744(13)\end{array}$ & $\begin{array}{l}90.00,117.868(4) \\
\quad 90.00\end{array}$ & $\begin{array}{l}76.612(2), 88.287(2), \\
83.816(2)\end{array}$ & $\begin{array}{l}75.053(3), 88.509(3), \\
86.951(3)\end{array}$ \\
\hline$V\left(\AA^{3}\right)$ & $6637.0(3)$ & $1768.42(7)$ & $1769.00(18)$ & $2058.58(16)$ & 2020.67 (18) \\
\hline$Z$ & 4 & 2 & 4 & 2 & 2 \\
\hline$D_{x}\left(\mathrm{Mg} \mathrm{m}^{-3}\right)$ & 1.219 & 1.209 & 1.252 & 1.218 & 1.224 \\
\hline Radiation type & Mo $K \alpha$ & Мо $K \alpha$ & Mo $K \alpha$ & Mo $K \alpha$ & Мо $K \alpha$ \\
\hline $\begin{array}{l}\text { No. of reflections for } \\
\text { cell parameters }\end{array}$ & 30027 & 8105 & 3291 & 9333 & 7517 \\
\hline$\theta$ range $\left(^{\circ}\right)$ & $2.6-27.5$ & $2.6-27.5$ & $2.8-25.5$ & $2.6-27.5$ & $2.6-25.5$ \\
\hline$\mu\left(\mathrm{mm}^{-1}\right)$ & 0.14 & 0.14 & 0.14 & 0.13 & 0.13 \\
\hline Temperature (K) & $150(1)$ & $150(1)$ & $150(1)$ & $150(1)$ & $150(1)$ \\
\hline Crystal form, colour & Block, colourless & Needle, colourless & Plate, colourless & Needle, colourless & Block, colourless \\
\hline Crystal size $(\mathrm{mm})$ & $0.34 \times 0.32 \times 0.12$ & $0.30 \times 0.28 \times 0.25$ & $0.44 \times 0.30 \times 0.04$ & $0.20 \times 0.12 \times 0.04$ & $0.24 \times 0.17 \times 0.10$ \\
\hline \multicolumn{6}{|l|}{ Data collection } \\
\hline Diffractometer & Kappa-CCD & Kappa-CCD & Kappa-CCD & Kappa-CCD & Kappa-CCD \\
\hline $\begin{array}{l}\text { Data collection } \\
\text { method }\end{array}$ & $\begin{array}{l}\varphi \text { scans, and } \\
\omega \text { scans with } \\
\kappa \text { offsets }\end{array}$ & $\begin{array}{l}\varphi \text { scans, and } \\
\omega \text { scans with } \\
\kappa \text { offsets }\end{array}$ & $\begin{array}{l}\varphi \text { scans, and } \\
\omega \text { scans with } \\
\kappa \text { offsets }\end{array}$ & $\begin{array}{l}\varphi \text { scans, and } \\
\omega \text { scans with } \\
\kappa \text { offsets }\end{array}$ & $\begin{array}{l}\varphi \text { scans, and } \\
\omega \text { scans with } \\
\kappa \text { offsets }\end{array}$ \\
\hline $\begin{array}{l}\text { Absorption } \\
\text { correction }\end{array}$ & Multi-scan & Multi-scan & None & None & None \\
\hline$T_{\min }$ & 0.972 & 0.914 & - & - & - \\
\hline$T_{\max }$ & 0.986 & 0.967 & - & - & - \\
\hline $\begin{array}{l}\text { No. of measured, } \\
\text { independent and } \\
\text { observed } \\
\text { reflections }\end{array}$ & $58413,30027,13026$ & $23113,8105,6126$ & 15 411, 3291, 2276 & $21083,9333,5498$ & $21774,7517,4671$ \\
\hline $\begin{array}{l}\text { Criterion for } \\
\text { observed } \\
\text { reflections }\end{array}$ & $I>2 \sigma(I)$ & $I>2 \sigma(I)$ & $I>2 \sigma(I)$ & $I>2 \sigma(I)$ & $I>2 \sigma(I)$ \\
\hline$R_{\text {int }}$ & 0.093 & 0.051 & 0.099 & 0.074 & 0.078 \\
\hline$\theta_{\max }\left({ }^{\circ}\right)$ & 27.5 & 27.5 & 25.5 & 27.5 & 25.5 \\
\hline Range of $h, k, l$ & $\begin{array}{l}-19 \Rightarrow h \Rightarrow 19 \\
-24 \Rightarrow k \Rightarrow 24 \\
-29 \Rightarrow l \Rightarrow 30\end{array}$ & $\begin{array}{l}-11 \Rightarrow h \Rightarrow 11 \\
-18 \Rightarrow k \Rightarrow 18 \\
-20 \Rightarrow l \Rightarrow 21\end{array}$ & $\begin{array}{l}-17 \Rightarrow h \Rightarrow 17 \\
-9 \Rightarrow k \Rightarrow 9 \\
-20 \Rightarrow l \Rightarrow 20\end{array}$ & $\begin{array}{l}-11 \Rightarrow h \Rightarrow 11 \\
-17 \Rightarrow k \Rightarrow 18 \\
-20 \Rightarrow l \Rightarrow 21\end{array}$ & $\begin{array}{l}-10 \Rightarrow h \Rightarrow 10 \\
-16 \Rightarrow k \Rightarrow 16 \\
-20 \Rightarrow l \Rightarrow 20\end{array}$ \\
\hline \multicolumn{6}{|l|}{ Refinement } \\
\hline $\begin{array}{c}R\left[F^{2}>2 \sigma\left(F^{2}\right)\right], \\
\quad w R\left(F^{2}\right), S\end{array}$ & $0.073,0.225,0.96$ & $0.041,0.109,1.02$ & $0.047,0.133,1.03$ & $0.059,0.155,1.02$ & $0.052,0.131,1.01$ \\
\hline No. of reflections & 30027 & 8105 & 3291 & 9333 & 7517 \\
\hline No. of parameters & 1331 & 427 & 237 & 499 & 490 \\
\hline $\mathrm{H}$-atom treatment & $\begin{array}{l}\text { Constrained to } \\
\text { parent site }\end{array}$ & $\begin{array}{l}\text { Constrained to } \\
\text { parent site }\end{array}$ & $\begin{array}{l}\text { Constrained to } \\
\text { parent site }\end{array}$ & $\begin{array}{l}\text { Constrained to } \\
\text { parent site }\end{array}$ & $\begin{array}{l}\text { Constrained to } \\
\text { parent site }\end{array}$ \\
\hline Weighting scheme & $\begin{aligned} w & =1 /\left[\sigma^{2}\left(F_{o}^{2}\right)\right. \\
& \left.+(0.1027 P)^{2}\right], \text { where } \\
& P=\left(F_{o}^{2}+2 F_{c}^{2}\right) / 3\end{aligned}$ & $\begin{aligned} w & =1 /\left[\sigma^{2}\left(F_{o}^{2}\right)\right. \\
& \left.+(0.0408 P)^{2}+0.511 P\right], \\
& \text { where } P=\left(F_{o}^{2}+2 F_{c}^{2}\right) / 3\end{aligned}$ & $\begin{aligned} w= & 1 /\left[\sigma^{2}\left(F_{o}^{2}\right)\right. \\
& \left.+(0.0714 P)^{2}\right], \text { where } \\
P & =\left(F_{o}^{2}+2 F_{c}^{2}\right) / 3\end{aligned}$ & $\begin{aligned} w & =1 /\left[\sigma^{2}\left(F_{o}^{2}\right)\right. \\
& +(0.0609 P)^{2} \\
& +0.2885 P] \\
& \text { where } P=\left(F_{o}^{2}+2 F_{c}^{2}\right) / 3\end{aligned}$ & $\begin{aligned} w & =1 /\left[\sigma^{2}\left(F_{o}^{2}\right)\right. \\
& \left.+(0.0493 P)^{2}+0.384 P\right], \\
& \text { where } P=\left(F_{o}^{2}+2 F_{c}^{2}\right) / 3\end{aligned}$ \\
\hline$(\Delta / \sigma)_{\max }$ & 0.001 & 0.001 & 0.004 & 0.001 & 0.001 \\
\hline $\begin{array}{l}\Delta \rho_{\max }, \Delta \rho_{\min } \\
\quad\left(\mathrm{e} \mathrm{A}^{-3}\right)\end{array}$ & $0.56,-0.47$ & $0.23,-0.31$ & $0.24,-0.40$ & $0.62,-0.33$ & $0.60,-0.46$ \\
\hline Extinction method & None & SHELXL & SHELXL & SHELXL & SHELXL \\
\hline $\begin{array}{l}\text { Extinction } \\
\text { coefficient }\end{array}$ & - & $0.0085(14)$ & $0.011(3)$ & $0.0072(12)$ & $0.0037(7)$ \\
\hline
\end{tabular}

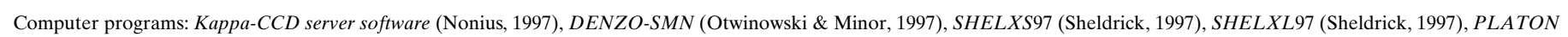
(Spek, 2003), PRPKAPPA (Ferguson, 1999), WINGX (Farrugia, 1999).

two sets of sites, with refined occupancies of 0.798 (3) and 0.202 (3), where the two set of sites have essentially identical $\mathrm{N}$ positions but the $-\mathrm{CH}_{2}-\mathrm{CH}_{2}-$ bridges in the two orien- tations are effectively rotated by $c a 60^{\circ}$ about the $\mathrm{N} \cdots \mathrm{N}$ vector: the $\mathrm{C}$ and $\mathrm{N}$ atoms of the minor component were refined isotropically. 
Table 2

Selected geometric parameters $\left(\AA{ }^{\circ}\right)$.

\begin{tabular}{|c|c|c|c|}
\hline $\begin{array}{l}\text { (a) } \mathrm{Si}-\mathrm{O} \text { distances } \\
\text { (I) }\end{array}$ & & & \\
\hline $\mathrm{Si} 1-\mathrm{O} 1$ & $1.637(2)$ & $\mathrm{Si} 2-\mathrm{O} 2$ & $1.631(2)$ \\
\hline $\mathrm{Si} 3-\mathrm{O} 3$ & $1.634(2)$ & $\mathrm{Si} 4-\mathrm{O} 4$ & $1.633(2)$ \\
\hline (II) & & & \\
\hline Si $1-O 1$ & $1.636(2)$ & $\mathrm{Si} 2-\mathrm{O} 2$ & $1.627(2)$ \\
\hline (III) & & & \\
\hline Si1-O1 & $1.624(2)$ & & \\
\hline (IV) & & & \\
\hline Si1-O1 & $1.633(2)$ & $\mathrm{Si} 2-\mathrm{O} 2$ & $1.630(2)$ \\
\hline$(\mathrm{V})$ & & & \\
\hline Si1-O1 & $1.640(2)$ & $\mathrm{Si} 2-\mathrm{O} 2$ & $1.634(2)$ \\
\hline $\begin{array}{l}\text { (b) Torsional and dihedral angle } \\
\text { (I) }\end{array}$ & & & \\
\hline $\mathrm{O} 1-\mathrm{Si} 1-\mathrm{C} 111-\mathrm{C} 112$ & $-83.6(2)$ & $\mathrm{O} 2-\mathrm{Si} 2-\mathrm{C} 211-\mathrm{C} 212$ & $-63.4(2)$ \\
\hline $\mathrm{O} 1-\mathrm{Si} 1-\mathrm{C} 121-\mathrm{C} 122$ & $18.6(2)$ & $\mathrm{O} 2-\mathrm{Si} 2-\mathrm{C} 221-\mathrm{C} 222$ & $-18.4(2)$ \\
\hline $\mathrm{O} 1-\mathrm{Si} 1-\mathrm{C} 131-\mathrm{C} 132$ & $0.6(2)$ & $\mathrm{O} 2-\mathrm{Si} 2-\mathrm{C} 231-\mathrm{C} 232$ & $-7.4(2)$ \\
\hline $\mathrm{O} 3-\mathrm{Si} 3-\mathrm{C} 311-\mathrm{C} 312$ & $59.5(2)$ & $\mathrm{O} 4-\mathrm{Si} 4-\mathrm{C} 411-\mathrm{C} 412$ & $56.0(2)$ \\
\hline $\mathrm{O} 3-\mathrm{Si} 3-\mathrm{C} 321-\mathrm{C} 322$ & $7.7(2)$ & $\mathrm{O} 4-\mathrm{Si} 4-\mathrm{C} 421-\mathrm{C} 422$ & $57.9(2)$ \\
\hline $\mathrm{O} 3-\mathrm{Si} 3-\mathrm{C} 331-\mathrm{C} 332$ & $61.1(2)$ & $\mathrm{O} 4-\mathrm{Si} 4-\mathrm{C} 431-\mathrm{C} 432$ & $10.6(2)$ \\
\hline $\mathrm{N} 11-\mathrm{C} 11-\mathrm{C} 12-\mathrm{N} 12$ & $-9.1(4)$ & & \\
\hline $\mathrm{N} 11-\mathrm{C} 13-\mathrm{C} 14-\mathrm{N} 12$ & $-8.9(4)$ & & \\
\hline $\mathrm{N} 11-\mathrm{C} 15-\mathrm{C} 16-\mathrm{N} 12$ & $-9.4(4)$ & & \\
\hline $\mathrm{N} 21-\mathrm{C} 21-\mathrm{C} 22-\mathrm{N} 22$ & $3.7(7)$ & $\mathrm{N} 31-\mathrm{C} 31-\mathrm{C} 32-\mathrm{N} 32$ & $-5(2)$ \\
\hline $\mathrm{N} 21-\mathrm{C} 23-\mathrm{C} 24-\mathrm{N} 22$ & $2.9(6)$ & $\mathrm{N} 31-\mathrm{C} 33-\mathrm{C} 34-\mathrm{N} 32$ & $-2(2)$ \\
\hline $\mathrm{N} 21-\mathrm{C} 25-\mathrm{C} 26-\mathrm{N} 22$ & $2.2(6)$ & $\mathrm{N} 31-\mathrm{C} 35-\mathrm{C} 36-\mathrm{N} 32$ & $-2(2)$ \\
\hline (II) & & & \\
\hline $\mathrm{O} 1-\mathrm{Si} 1-\mathrm{C} 11-\mathrm{C} 12$ & $-43.5(2)$ & $\mathrm{O} 2-\mathrm{Si} 2-\mathrm{C} 41-\mathrm{C} 42$ & $-5.8(2)$ \\
\hline $\mathrm{O} 1-\mathrm{Si} 1-\mathrm{C} 21-\mathrm{C} 22$ & $-39.6(2)$ & $\mathrm{O} 2-\mathrm{Si} 2-\mathrm{C} 51-\mathrm{C} 52$ & $-75.6(2)$ \\
\hline $\mathrm{O} 1-\mathrm{Si} 1-\mathrm{C} 31-\mathrm{C} 32$ & $-33.6(2)$ & $\mathrm{O} 2-\mathrm{Si} 2-\mathrm{C} 61-\mathrm{C} 62$ & $17.2(2)$ \\
\hline$(\mathrm{N} 1-\mathrm{C} 6)^{\wedge}\left(\mathrm{C} 4-\mathrm{C} 7-\mathrm{C} 7^{\mathrm{i}}-\mathrm{C} 4^{\mathrm{i}}\right)$ & $10.0(2)$ & & \\
\hline (III) & & & \\
\hline $\mathrm{O} 1-\mathrm{Si} 1-\mathrm{C} 11-\mathrm{C} 12$ & $-46.8(2)$ & & \\
\hline $\mathrm{O} 1-\mathrm{Si} 1-\mathrm{C} 21-\mathrm{C} 22$ & $-42.9(2)$ & & \\
\hline $\mathrm{O} 1-\mathrm{Si} 1-\mathrm{C} 31-\mathrm{C} 32$ & $-24.1(2)$ & & \\
\hline (IV) & & & \\
\hline $\mathrm{O} 1-\mathrm{Si} 1-\mathrm{C} 111-\mathrm{C} 112$ & $7.9(2)$ & $\mathrm{O} 2-\mathrm{Si} 2-\mathrm{C} 211-\mathrm{C} 212$ & $-47.2(2)$ \\
\hline $\mathrm{O} 1-\mathrm{Si} 1-\mathrm{C} 121-\mathrm{C} 122$ & $-0.8(2)$ & $\mathrm{O} 2-\mathrm{Si} 2-\mathrm{C} 221-\mathrm{C} 222$ & $-66.2(2)$ \\
\hline $\mathrm{O} 1-\mathrm{Si} 1-\mathrm{C} 131-\mathrm{C} 132$ & $56.6(2)$ & $\mathrm{O} 2-\mathrm{Si} 2-\mathrm{C} 231-\mathrm{C} 232$ & $-43.2(2)$ \\
\hline $\mathrm{C} 13-\mathrm{C} 14-\mathrm{C} 17-\mathrm{C} 27$ & $-154.8(3)$ & $\mathrm{C} 14-\mathrm{C} 17-\mathrm{C} 27-\mathrm{C} 24$ & $169.3(3)$ \\
\hline $\mathrm{C} 23-\mathrm{C} 24-\mathrm{C} 27-\mathrm{C} 17$ & $-119.6(3)$ & & \\
\hline$(\mathrm{V})$ & & & \\
\hline $\mathrm{O} 1-\mathrm{Si} 1-\mathrm{C} 111-\mathrm{C} 112$ & $-60.9(2)$ & $\mathrm{O} 2-\mathrm{Si} 2-\mathrm{C} 211-\mathrm{C} 212$ & $-4.7(2)$ \\
\hline $\mathrm{O} 1-\mathrm{Si} 1-\mathrm{C} 121-\mathrm{C} 122$ & $-61.5(2)$ & $\mathrm{O} 2-\mathrm{Si} 2-\mathrm{C} 221-\mathrm{C} 222$ & $10.9(2)$ \\
\hline $\mathrm{O} 1-\mathrm{Si} 1-\mathrm{C} 131-\mathrm{C} 132$ & $-40.6(2)$ & $\mathrm{O} 2-\mathrm{Si} 2-\mathrm{C} 231-\mathrm{C} 232$ & $-59.6(2)$ \\
\hline$(\mathrm{N} 1-\mathrm{C} 16)^{\wedge}(\mathrm{N} 2-\mathrm{C} 26)$ & $35.3(2)$ & & \\
\hline
\end{tabular}

Symmetry code: (i) $1-x, 1-y, 1-z$.

Supramolecular analyses were made and the diagrams were prepared with the aid of PLATON (Spek, 2003). Details of selected molecular dimensions and hydrogen-bond dimensions are given in Tables 2 and 3. ${ }^{\mathbf{1}}$ Figs. 1-14 show the mole-

\footnotetext{
${ }^{\mathbf{1}}$ Supplementary data for this paper are available from the IUCr electronic archives (Reference: NA5012). Services for accessing these data are described at the back of the journal.
}

cular components, with the atom-labelling schemes, and aspects of the supramolecular structures.

\section{Results and discussion}

\subsection{Crystallization characteristics}

For each of the amines $(C)$ and $(E)$ [see Scheme (I)], co-crystallization with triphenylsilanol from solution in dry methanol containing molar ratios of triphenylsilanol-to-amine of $1: 1,2: 1$ or $4: 1$ consistently provided pure samples of the $4: 1$ adducts (II) and(I), respectively. Similar mixtures of triphenylsilanol with the amines $(B)$ and $(F)$ consistently yielded the mono-hydrated $2: 1$ adduct (IV) and the solvent-free 2:1 adduct (III), respectively. This behaviour may be contrasted with that of mixtures of triphenylsilanol with $(B)$, again in dry methanol, where a 1:1 molar ratio yielded a $1: 1$ adduct, but where both $2: 1$ and $4: 1$ molar ratios gave concomitant polymorphs of the 4:1 adduct (Bowes et al., 2003): presumably in the formation of (IV), the water has an atmospheric origin. However, when deliberately damp methanol was employed as the solvent for an equimolar mixture of triphenylsilanol with $(B)$, the product was not the expected 1:1 adduct, but instead the hydrated 2:1 adduct (V). All attempts to obtain adducts of triphenylsilanol with the amines $(G)$ and $(H)$ have so far been unsuccessful.

It is notable that in (I) and (II), the 4:1 aggregates formed by the hard hydrogen bonds have all of their triphenylsilanol components fully ordered. This is in marked contrast to the various polymorphs of the 4:1 adduct formed between triphenylsilanol and 4,4'-bipyridyl, where there is very extensive orientational disorder of the phenyl groups, even at $150 \mathrm{~K}$ (Bowes et al., 2003). In triphenylsilanol itself, the phenyl disorder is modest at low temperatures, but intractable at ambient temperatures (Bowes et al., 2002).

By contrast with the reactions involving triphenylsilanol and the amines $(B)-(F)$, these amines with triphenylmethanol, $\mathrm{Ph}_{3} \mathrm{COH}$, in methanol solutions consistently gave pure triphenylmethanol as the sole crystalline product, regardless of whether the input molar ratio of triphenylmethanol to amine was $1: 1,2: 1$ or $4: 1$.

\subsection{Dimensions and conformations}

The independent $\mathrm{Si}-\mathrm{O}$ distances in (I)-(V) (Table 2) span the rather narrow range 1.624 (2)-1.640 (2) A and no individual value is markedly different from the values (Bowes et al., 2002, 2003) in tetrameric triphenylsilanol itself or in its 4:1 adduct with 1,4-dioxan, mean values 1.645 (6) and 1.639 (2) A, respectively; in the $Z^{\prime}=0.5$ and $Z^{\prime}=1$ polymorphs of the $4: 1$ adduct of triphenylsilanol with 4,4'-bipyridyl, mean values 
1.633 (4) and 1.634 (7) $\AA$, respectively; or in the $1: 1$ adduct formed with 4,4'-bipyridyl, 1.629 (2), and in the 2:1 adduct formed with dimethylsulfoxide, 1.636 (2) $\AA$.

The highest possible symmetry for the non- $\mathrm{H}$ atoms in a triphenylsilanol molecule is $C_{3 v}(3 m)$ and there are two conformations, defined by $\mathrm{O}-\mathrm{Si}-\mathrm{C}-\mathrm{C}$ torsional angles of zero or $90^{\circ}$, respectively, which have this symmetry. In the event, the inner triphenylsilanol molecule in (II), containing Si1, the unique triphenylsilanol molecule in (III) and one of the triphenylsilanol molecules in each of (IV) and (V), those containing Si2 and Si1, respectively, all have conformations fairly close to $C_{3}$ (3) symmetry for the non- $\mathrm{H}$ atoms: the numerical values of the $\mathrm{O}-\mathrm{Si}-\mathrm{C}-\mathrm{C}$ torsional angles in these components lie in the range 24.1 (2) to $66.2(2)^{\circ}$ with a mean of $c a 46^{\circ}$, just midway between the two $C_{3 v}$ conformations. However, only one of the triphenylsilanol molecules, that in (III) containing $\mathrm{Si} 2$, has a conformation close to $C s(m)$ symmetry for the non- $\mathrm{H}$ atoms. In this molecule the $\mathrm{O}-\mathrm{Si}-$ $\mathrm{C}-\mathrm{C}$ torsional angle for one phenyl ring is close to $90^{\circ}$ and those for the other two rings are close to zero, but with opposite signs (Table 2). The remaining independent triphenylsilanol molecules have conformations in which the non- $\mathrm{H}$ atoms do not even approximate to any symmetry above $C_{1}$.

The fully ordered DABCO unit in (I) exhibits the usual twist away from $D_{3 h}(\overline{6} m 2)$ symmetry towards $D_{3}$ (32) symmetry, with a mean $\mathrm{N}-\mathrm{C}-\mathrm{C}-\mathrm{N}$ torsional angle of $9.1(4)^{\circ}$. The major component of the disordered DABCO shows a much smaller distortion, with a mean $\mathrm{N}-\mathrm{C}-\mathrm{C}-\mathrm{N}$ torsional angle of $2.9(6)^{\circ}$, while for the minor component the mean $\mathrm{N}-\mathrm{C}-\mathrm{C}-\mathrm{N}$ torsional angle is not significantly different from zero.

In each of compounds (I) and (II) the $\mathrm{O}-\mathrm{H} \cdots \mathrm{N}$ hydrogen bonds are shorter than the $\mathrm{O}-\mathrm{H} \cdots \mathrm{O}$ hydrogen bonds, although the difference is less marked in (II) than in (I). In (IV) and (V) the $\mathrm{O}-\mathrm{H} \cdots \mathrm{O}$ hydrogen bonds involving triphenylsilanol as a donor and water as an acceptor are markedly shorter than those involving water as a donor and triphenylsilanol as an acceptor. In (V) both of the hydrogen bonds, to $\mathrm{N}$ as well as to $\mathrm{O}$ as an acceptor, are markedly shorter with $\mathrm{O} 21$ as a donor as compared with $\mathrm{O} 11$ as a donor.

\subsection{Supramolecular structures}

3.3.1. Hydrogen bonds generate a finite, zero-dimensional aggregate. The hard (Braga et al., 1995; Desiraju \& Steiner, 1999) hydrogen bonds generate two independent fivecomponent aggregates in the $4: 1$ adduct (I), both of which lie in general positions in the space group $P \overline{1}$; in each aggregate an inner pair of triphenylsilanol molecules is linked to a $\mathrm{DABCO}$ unit via $\mathrm{O}-\mathrm{H} \cdots \mathrm{N}$ hydrogen bonds, with an outer pair of triphenylsilanol molecules again linked to the first pair via $\mathrm{O}-\mathrm{H} \cdots \mathrm{O}$ hydrogen bonds (Fig. 1). While all 24 of the independent phenyl rings in (I) are fully ordered, only one of the DABCO units is so ordered. In aggregate 1 , containing $\mathrm{N} 11$ and N12, the DABCO is fully ordered, but in aggregate 2, containing $\mathrm{N} 21$ and $\mathrm{N} 22$, there are two orientations of the DABCO unit, related by a rotation of approximately $60^{\circ}$

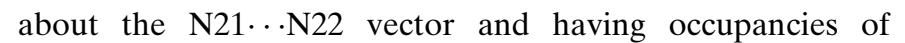
0.798 (3) and 0.202 (3), respectively.

There are two significant $\mathrm{C}-\mathrm{H} \cdots \pi$ (arene) hydrogen bonds in (I) which serve to link the two independent five-component aggregates into a single ten-component unit. Atoms $\mathrm{C} 134$ and C724 act as hydrogen-bond donors, respectively, to rings C621-C626 and C411-C416, thus producing an aggregate in which two DABCO and six triphenylsilanol molecules are linked into a large rectangular ring, with the two remaining triphenylsilanol molecules pendent from it (Fig. 2).

Each of the two independent five-component aggregates has a pseudo-inversion centre at the centre of the DABCO moiety. One DABCO molecule (N11-C16) is centred at approximately $\left(\frac{1}{2}, \frac{1}{2}, \frac{1}{4}\right)$ and the other (N21-C26) is centred at approximately $\left(\frac{1}{2}, 0, \frac{1}{4}\right)$. This overall 10 -molecule aggregate is approximately centrosymmetric about the point $\left(\frac{1}{2}, \frac{3}{4}, \frac{1}{4}\right)$, but the disorder of the type 2 DABCO molecule and the detailed conformations of the triphenylsilanol components (see above, $\S 3.2)$ both preclude the possibility of any additional symmetry.

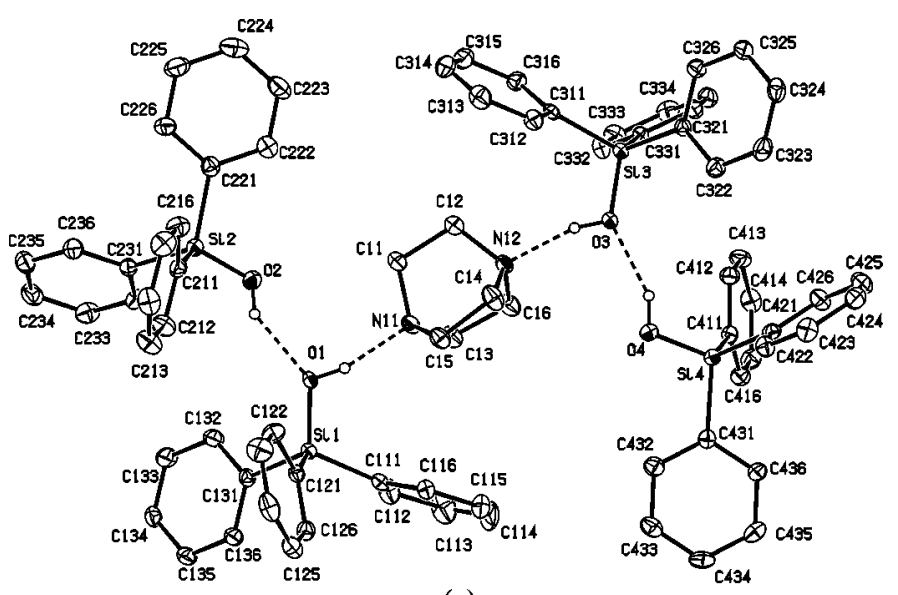

(a)

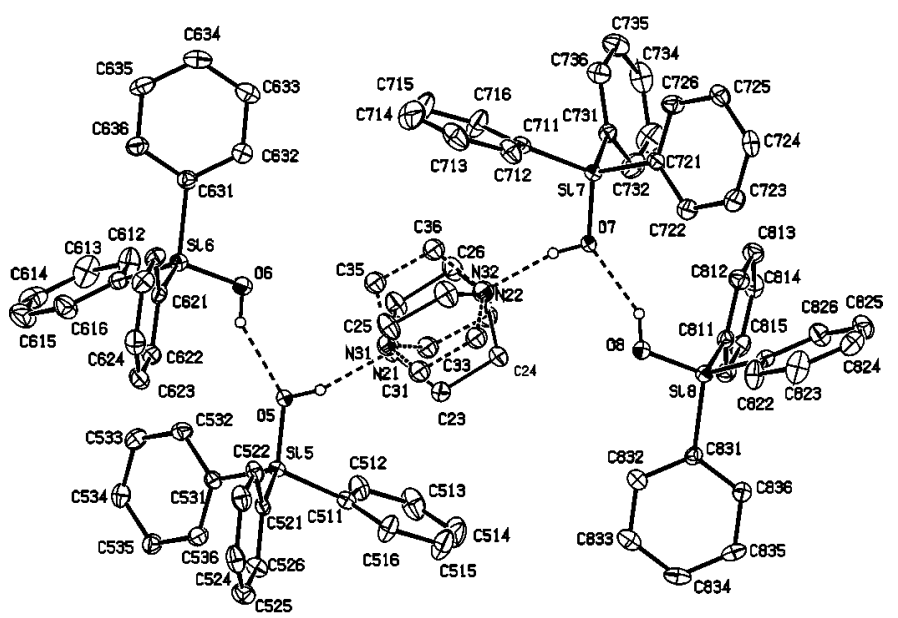

(b)

Figure 1

The two independent five-component aggregates in (I), showing the atom-labelling scheme: $(a)$ aggregate 1 containing a fully ordered DABCO unit; $(b)$ aggregate 2 containing a disordered DABCO unit (see text). Displacement ellipsoids are drawn at the $30 \%$ probability level and the $\mathrm{H}$ atoms bonded to $\mathrm{C}$ atoms are omitted for the sake of clarity. 
Table 3

Hydrogen-bond parameters $\left(\AA{ }^{\circ}\right)$.

\begin{tabular}{|c|c|c|c|}
\hline$\overline{D-\mathrm{H} \cdots A}$ & $\mathrm{H} \cdots A$ & $D \cdots A$ & $D-\mathrm{H} \cdots A$ \\
\hline \multicolumn{4}{|l|}{ (I) } \\
\hline $\mathrm{O} 1-\mathrm{H} 1 \cdots \mathrm{N} 11$ & 1.82 & $2.642(3)$ & 165 \\
\hline $\mathrm{O} 2-\mathrm{H} 2 \cdots \mathrm{O} 1$ & 2.01 & $2.727(3)$ & 143 \\
\hline $\mathrm{O} 3-\mathrm{H} 3 \cdots \mathrm{N} 12$ & 1.82 & $2.642(3)$ & 164 \\
\hline $\mathrm{O} 4-\mathrm{H} 4 \cdots \mathrm{O} 3$ & 1.95 & $2.729(3)$ & 153 \\
\hline $\mathrm{O} 5-\mathrm{H} 5 \cdots \mathrm{N} 21$ & 1.80 & $2.620(6)$ & 164 \\
\hline $\mathrm{O} 6-\mathrm{H} 6 \cdots \mathrm{O} 5$ & 2.00 & $2.736(3)$ & 146 \\
\hline $\mathrm{O} 7-\mathrm{H} 7 \cdots \mathrm{N} 22$ & 1.81 & $2.633(7)$ & 164 \\
\hline $\mathrm{O} 8-\mathrm{H} 8 \cdots \mathrm{O} 7$ & 1.96 & $2.701(3)$ & 146 \\
\hline $\mathrm{C} 134-\mathrm{H} 134 \cdots \mathrm{Cg} 1^{a, \mathrm{i}}$ & 2.79 & $3.576(3)$ & 141 \\
\hline $\mathrm{C} 724-\mathrm{H} 724 \cdots \mathrm{Cg} 2^{b, \mathrm{ii}}$ & 2.68 & $3.536(3)$ & 150 \\
\hline \multicolumn{4}{|l|}{ (II) } \\
\hline $\mathrm{O} 1-\mathrm{H} 1 \cdots \mathrm{N} 1$ & 1.85 & $2.653(2)$ & 159 \\
\hline $\mathrm{O} 2-\mathrm{H} 2 \cdots \mathrm{O} 1$ & 1.98 & $2.691(2)$ & 142 \\
\hline $\mathrm{C} 33-\mathrm{H} 33 \cdots \mathrm{Cg} 3^{c, \mathrm{ii}}$ & 2.69 & $3.635(2)$ & 173 \\
\hline \multicolumn{4}{|l|}{ (III) } \\
\hline $\mathrm{O} 1-\mathrm{H} 1 \cdots \mathrm{N} 1$ & 1.92 & $2.721(2)$ & 159 \\
\hline $\mathrm{C} 13-\mathrm{H} 13 \cdots \mathrm{Cg}^{c, \text { iii }}$ & 2.94 & $3.821(3)$ & 154 \\
\hline $\mathrm{C} 23-\mathrm{H} 23 \cdots \mathrm{Cg} 3^{c, \mathrm{iv}}$ & 2.93 & $3.746(3)$ & 145 \\
\hline \multicolumn{4}{|l|}{ (IV) } \\
\hline $\mathrm{O} 1-\mathrm{H} 1 \cdots \mathrm{O}^{\mathrm{v}}$ & 1.85 & $2.641(3)$ & 161 \\
\hline $\mathrm{O} 2-\mathrm{H} 2 \cdots \mathrm{N} 2$ & 1.96 & $2.753(3)$ & 163 \\
\hline $\mathrm{O} 3-\mathrm{H} 31 \cdots \mathrm{O} 1$ & 1.90 & $2.801(2)$ & 167 \\
\hline $\mathrm{O} 3-\mathrm{H} 32 \cdots \mathrm{N} 1$ & 1.88 & $2.791(3)$ & 170 \\
\hline $\mathrm{C} 16-\mathrm{H} 16 \cdots \mathrm{Cg} 4^{d, \mathrm{vi}}$ & 2.91 & $3.782(3)$ & 153 \\
\hline $\mathrm{C} 23-\mathrm{H} 23 \cdots \mathrm{Cg} 5^{e, \mathrm{vii}}$ & 2.75 & $3.440(3)$ & 130 \\
\hline $\mathrm{C} 115-\mathrm{H} 115 \cdots \mathrm{Cg} 6^{f, \text { viii }}$ & 2.94 & $3.757(3)$ & 145 \\
\hline $\mathrm{C} 214-\mathrm{H} 214 \cdots \mathrm{Cg} 7^{g, \mathrm{ix}}$ & 2.75 & $3.621(3)$ & 152 \\
\hline $\mathrm{C} 224-\mathrm{H} 224 \cdots \mathrm{Cg} 8^{h, \mathrm{x}}$ & 2.81 & $3.622(3)$ & 144 \\
\hline $\mathrm{C} 235-\mathrm{H} 235 \cdots \mathrm{Cg} 5^{e, \mathrm{xi}}$ & 2.77 & $3.603(3)$ & 147 \\
\hline \multicolumn{4}{|l|}{$(\mathrm{V})$} \\
\hline $\mathrm{O} 1-\mathrm{H} 1 \cdots \mathrm{O} 11$ & 1.84 & $2.660(3)$ & 164 \\
\hline $\mathrm{O} 2-\mathrm{H} 2 \cdots \mathrm{O} 21$ & 1.85 & $2.640(3)$ & 156 \\
\hline $\mathrm{O} 11-\mathrm{H} 11 A \cdots \mathrm{N} 1$ & 1.83 & $2.817(3)$ & 175 \\
\hline $\mathrm{O} 11-\mathrm{H} 11 B \cdots \mathrm{O} 1^{\mathrm{xii}}$ & 1.86 & $2.817(3)$ & 162 \\
\hline $\mathrm{O} 21-\mathrm{H} 21 A \cdots \mathrm{N} 2$ & 1.75 & $2.730(4)$ & 170 \\
\hline $\mathrm{O} 21-\mathrm{H} 21 B \cdots \mathrm{O} 2^{\mathrm{xiii}}$ & 1.81 & $2.678(3)$ & 144 \\
\hline $\mathrm{C} 114-\mathrm{H} 114 \cdots \mathrm{Cg} 4^{d, \mathrm{xiv}}$ & 2.87 & $3.717(3)$ & 148 \\
\hline $\mathrm{C} 124-\mathrm{H} 124 \cdots \mathrm{Cg} 5^{e, \mathrm{xv}}$ & 2.82 & $3.635(3)$ & 145 \\
\hline $\mathrm{C} 135-\mathrm{H} 135 \cdots \mathrm{Cg} 8^{h, \mathrm{xvi}}$ & 2.82 & $3.660(3)$ & 148 \\
\hline $\mathrm{C} 215-\mathrm{H} 215 \cdots \mathrm{Cg} 9^{j, \mathrm{xvii}}$ & 2.83 & $3.659(3)$ & 147 \\
\hline
\end{tabular}

Footnotes: (a) $\mathrm{Cg} 1$ is the centroid of the ring $\mathrm{C} 621-\mathrm{C} 626 ;(b) \mathrm{Cg} 2$ is the centroid of the ring $\mathrm{C} 411-\mathrm{C} 416$; (c) $\mathrm{Cg} 3$ is the centroid of the ring $\mathrm{C} 21-\mathrm{C} 26$; $(d) \mathrm{Cg} 4$ is the centroid of the ring $\mathrm{C} 221-\mathrm{C} 226$; $(e) \mathrm{Cg} 5$ is the centroid of the ring $\mathrm{C} 211-\mathrm{C} 216$; $(f) \mathrm{Cg} 6$ is the centroid of the ring $\mathrm{C} 131-\mathrm{C} 136 ;(\mathrm{g}) \mathrm{Cg} 7$ is the centroid of the ring $\mathrm{C} 121-\mathrm{C} 126 ;(h) \mathrm{Cg} 8$ is the centroid of the ring C111-C116; ( $j$ ) $\mathrm{Cg} 9$ is the centroid of the ring C231-C236; Symmetry codes: (i) $x, 1+y, z$; (ii) $-1+x, y, z$; (iii) $x,-1+y, z$; (iv) $2-x, \frac{1}{2}+y, \frac{3}{2}-z$; (v) $1-x, 1-y, 1-z$; (vi) $3-x, 1-y, 2-z$; (vii) $-1+x, y, z$; (viii) $1-x,-y, 1-z$; (ix) $2+x, y, z ; \quad$ (x) $2+x, y, 1+z ; \quad$ (xi) $4-x,-y, 2-z ; \quad$ (xii) $3-x,-y, 1-z ;$ (xiii) $-x,-y,-z$; (xiv) $2-x,-y,-z$; (xv) $2-x,-y, 1-z$; (xvi) $3-x,-1-y, 1-z$; (xvii) $-x, 1-y,-z$.

3.3.2. Hydrogen bonds generate a one-dimensional structure. In the $4: 1$ adduct (II), the 1,2-bis(4-pyridyl)ethene unit lies across a centre of inversion in the space group $P \overline{1}$, selected for the sake of convenience as that at $\left(\frac{1}{2}, \frac{1}{2}, \frac{1}{2}\right)$. Two triphenylsilanol molecules are linked to the diamine via short $\mathrm{O}-$ $\mathrm{H} \cdots \mathrm{N}$ hydrogen bonds and a further pair of triphenylsilanol molecules are linked to the first pair via short $\mathrm{O}-\mathrm{H} \cdots \mathrm{O}$ hydrogen bonds. The five-component molecular aggregate (Fig. 3) generated in (I) by the hard hydrogen bonds is thus very similar to that found in each of the polymorphs of the $4: 1$ adduct formed with 4,4'-bipyridyl.

However, a striking difference between the adducts formed by 4,4'-bipyridyl and 1,2-bis(4-pyridyl)ethene lies in the degree of disorder: whereas all three polymorphs of the $4,4^{\prime}$ bipyridyl adduct exhibit extensive disorder, all components of the 1,2-bis(4-pyridyl)ethene (I) are fully ordered. It is therefore possible to analyse in a straightforward way the effect of the soft (Braga et al., 1995; Desiraju \& Steiner, 1999) C$\mathrm{H} \cdots \pi$ (arene) hydrogen bonding in (II), where there is a single such interaction of structural significance. The aromatic atom C33 in the type 1 silanol molecule (containing Si1) at $(x, y, z)$ lies in the five-component aggregate centred at $\left(\frac{1}{2}, \frac{1}{2}, \frac{1}{2}\right)$, and it acts as a hydrogen-bond donor to the aromatic ring $\mathrm{C} 21-\mathrm{C} 26$ in the type 1 silanol at $(-1+x, y, z)$, which is part of the

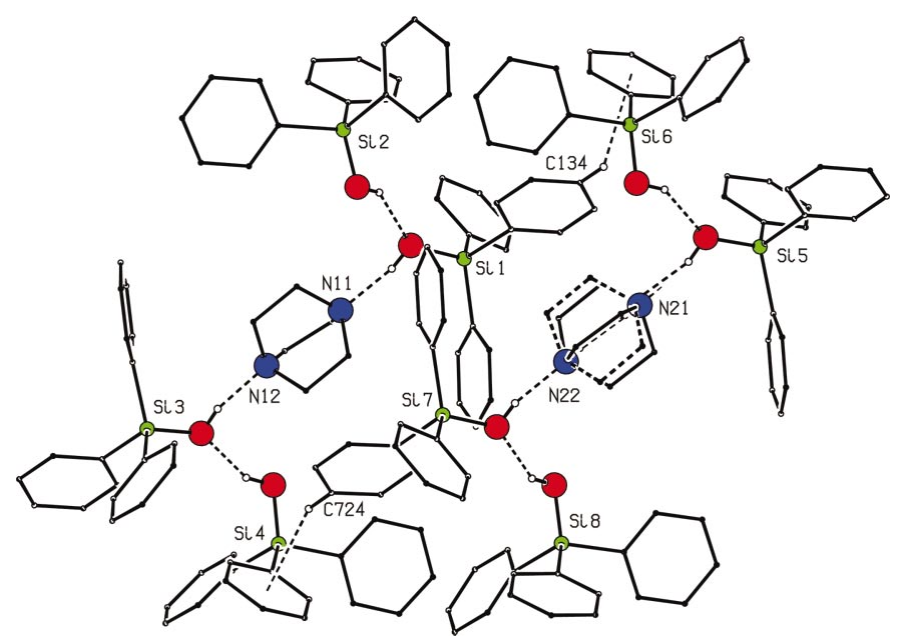

Figure 2

Part of the crystal structure of (I) showing the formation of a tenmolecule aggregate. For the sake of clarity, the $\mathrm{H}$ atoms bonded to $\mathrm{C}$ atoms and the unit-cell box are omitted.

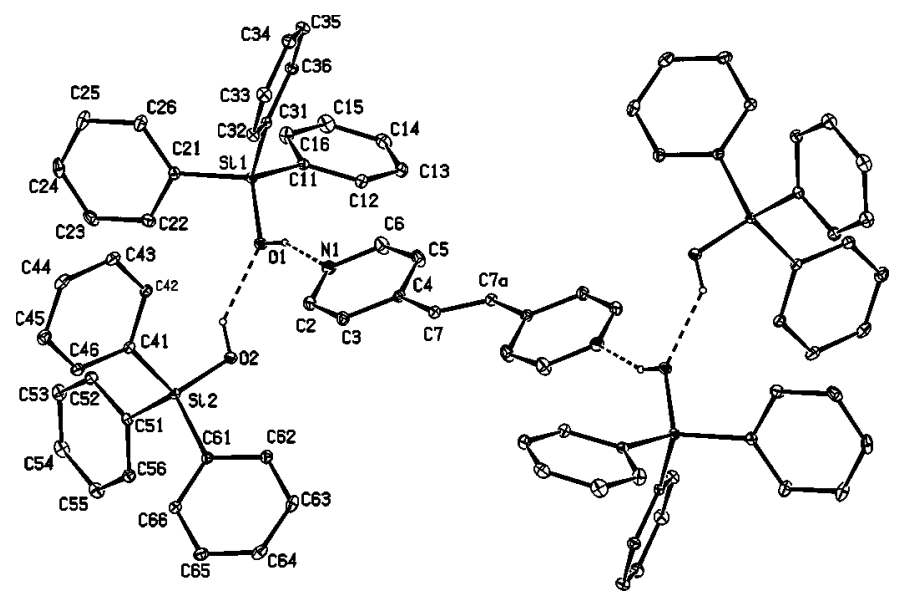

Figure 3

The five-component aggregate in (II), showing the atom-labelling scheme: the atom marked 'a' is at the symmetry position $(1-x, 1-y, 1-z)$. Displacement ellipsoids are drawn at the $10 \%$ probability level and the $\mathrm{H}$ atoms bonded to the $\mathrm{C}$ atoms are omitted for the sake of clarity. 
aggregate centred at $\left(-\frac{1}{2}, \frac{1}{2}, \frac{1}{2}\right)$. Propagation of this interaction by translation and inversion thus generates a chain of edgefused rings, alternatively regarded as a molecular ladder, running parallel to the [100] direction (Fig. 4).

3.3.3. Hydrogen bonds generate a two-dimensional structure. Compound (III) (Fig. 5) is a solvent-free 2:1 adduct in which the $N, N^{\prime}$-dimethylpiperazine component lies across a centre of inversion, selected as that at $\left(\frac{1}{2}, \frac{1}{2}, \frac{1}{2}\right)$ with the

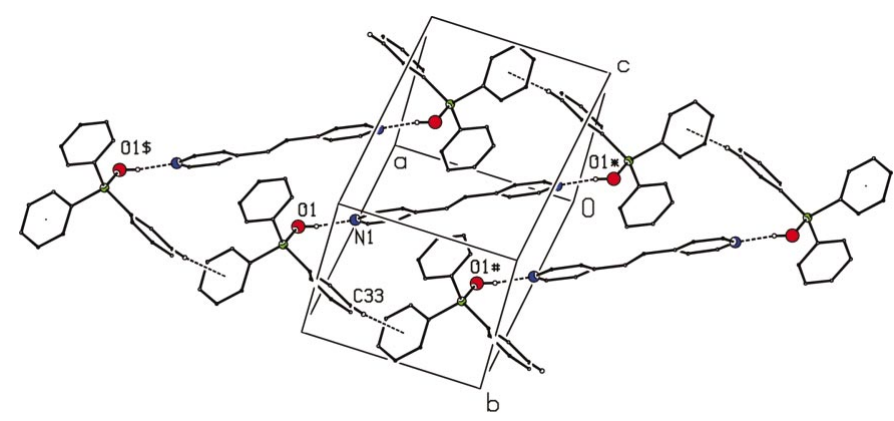

Figure 4

Part of the crystal structure of (II) showing the formation of a molecular ladder along [100]. For the sake of clarity, the outer triphenylsilanol molecules (containing $\mathrm{Si} 2$ ) and the $\mathrm{H}$ atoms bonded to $\mathrm{C}$ atoms are omitted. The atoms marked with an asterisk $(*)$, a hash (\#) or a dollar sign $(\$)$ are at the symmetry positions $(1-x, 1-y, 1-z),(-1+x, y, z)$ and $(1+x, y, z)$, respectively.

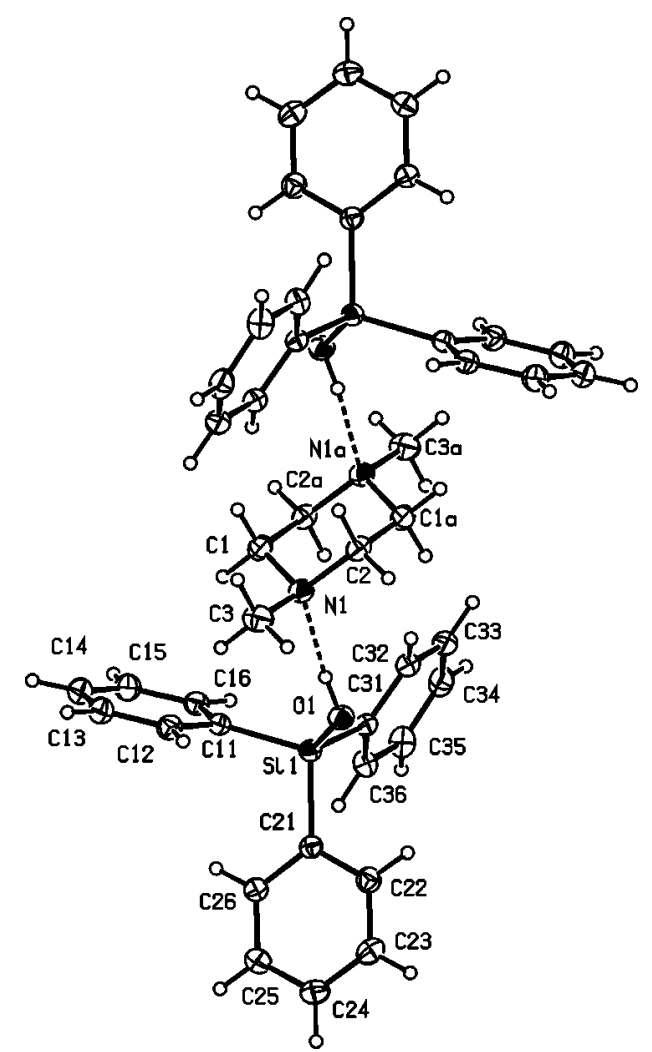

Figure 5

The three-component aggregate in (III) showing the atom-labelling scheme. Displacement ellipsoids are drawn at the $30 \%$ probability level and the atoms marked ' $a$ ' are at the symmetry position $(1-x, 1-y, 1-z)$. triphenylsilanol molecules linked to it via a unique $\mathrm{O}-\mathrm{H} \cdots \mathrm{N}$ hydrogen bond (Table 3) to form a centrosymmetric threecomponent aggregate. There are no aromatic $\pi \cdots \pi$ stacking interactions in the structure of (III), but two independent $\mathrm{C}-$ $\mathrm{H} \cdots \pi$ (arene) hydrogen bonds link the molecules into sheets: it is convenient to consider each of these interactions in turn as the substructures which they generate are entirely different.

In the first of these soft hydrogen bonds, the phenyl C13 atom in the molecule at $(x, y, z)$, which lies in the threemolecule aggregate centred at $\left(\frac{1}{2}, \frac{1}{2}, \frac{1}{2}\right)$, acts as a hydrogen-bond donor to the phenyl ring $\mathrm{C} 21-\mathrm{C} 26$ in the molecule at $(x,-1+y, z)$, a part of the three-molecule aggregate centred at $\left(\frac{1}{2},-\frac{1}{2}, \frac{1}{2}\right)$. Propagation of this hydrogen bond by translation and inversion generates a chain of edge-fused rings, or a molecular ladder, running parallel to the [010] direction (Fig. 6).

By contrast with this one-dimensional substructure the second $\mathrm{C}-\mathrm{H} \cdots \pi$ (arene) hydrogen bond generates a twodimensional substructure. The phenyl atom C23 in the molecule at $(x, y, z)$ acts as a donor to the ring $\mathrm{C} 21-\mathrm{C} 26$ in the molecule at $\left(2-x, \frac{1}{2}+y, \frac{3}{2}-z\right)$, which is part of the threemolecule aggregate centred at $\left(\frac{3}{2}, 1,1\right)$; the ring C21-C26 in the molecule at $(x, y, z)$ itself accepts a similar hydrogen bond from the $\mathrm{C} 23$ atom in the molecule at $\left(2-x,-\frac{1}{2}+y, \frac{3}{2}-z\right)$, which is part of the three-molecule aggregate centred at $\left(\frac{3}{2}, 0\right.$, $1)$. The action of the inversion centre at $\left(\frac{1}{2}, \frac{1}{2}, \frac{1}{2}\right)$ also links the reference aggregate centred at $\left(\frac{1}{2}, \frac{1}{2}, \frac{1}{2}\right)$ directly to those centred at $\left(-\frac{1}{2}, 0,0\right)$ and $\left(-\frac{1}{2}, 1,0\right)$. Hence, this single soft hydrogen bond links each three-molecule aggregate to four others, thus generating a sheet parallel to (10人) (Fig. 7). If the threecomponent aggregates are regarded as the nodes of the

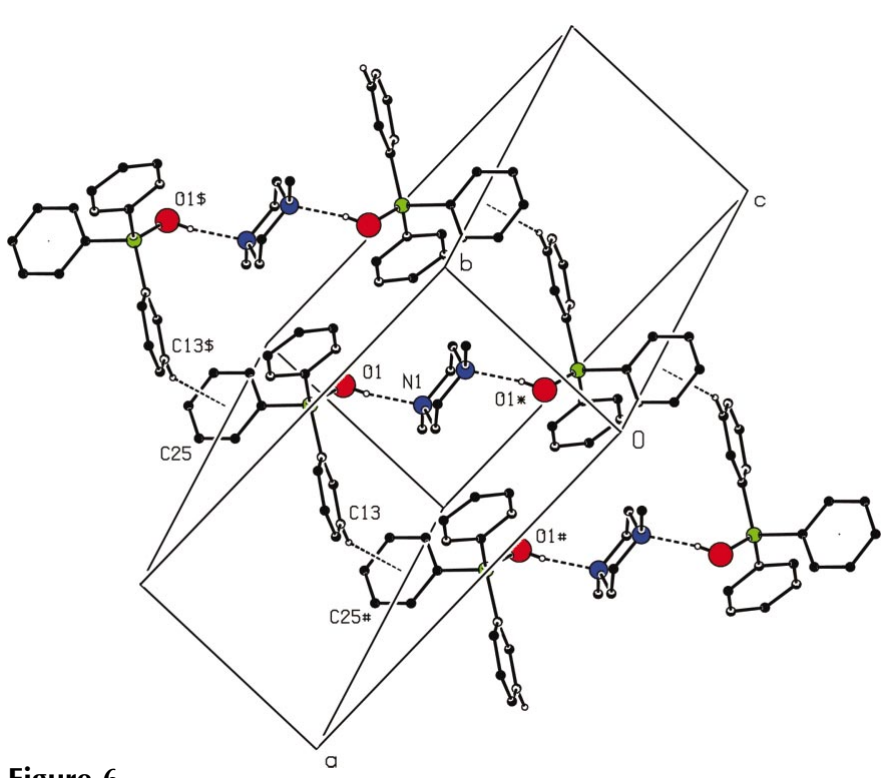

Part of the crystal structure of (III) showing the formation of a molecular ladder along [010]. For the sake of clarity the $\mathrm{H}$ atoms bonded to $\mathrm{C}$ atoms, but not involved in the hydrogen-bond motif shown, are omitted. The atoms marked with an asterisk (*), a hash (\#) or a dollar sign (\$) are at the symmetry positions $(1-x, 1-y, 1-z),(x,-1+y, z)$ and $(x, 1+y, z)$, respectively. 
corresponding net, this is of the $(4,4)$ type (Batten \& Robson, 1998).

3.3.4. Hydrogen bonds generate a three-dimensional structure. Hard hydrogen bonds generate a finite aggregate: The hard hydrogen bonds in (IV) link the four independent molecular components into a finite, centrosymmetric aggregate of eight molecules (Fig. 8), where all of the individual components lie in general positions. The diamine unit acts as a double acceptor of $\mathrm{O}-\mathrm{H} \cdots \mathrm{N}$ hydrogen bonds, one from the water molecule via $\mathrm{H} 32$ and one from the triphenylsilanol molecule containing Si2 (Table 3). The water molecule also acts as a hydrogen-bond donor, via $\mathrm{H} 31$, to triphenylsilanol $\mathrm{O} 1$ within the asymmetric unit, while $\mathrm{O} 1$ at $(x, y, z)$ in turn acts as a donor to the water atom $\mathrm{O} 3$ at $(1-x, 1-y, 1-z)$. Hence, a centrosymmetric $R_{4}^{4}(8)$ ring is generated, lying at the centre of
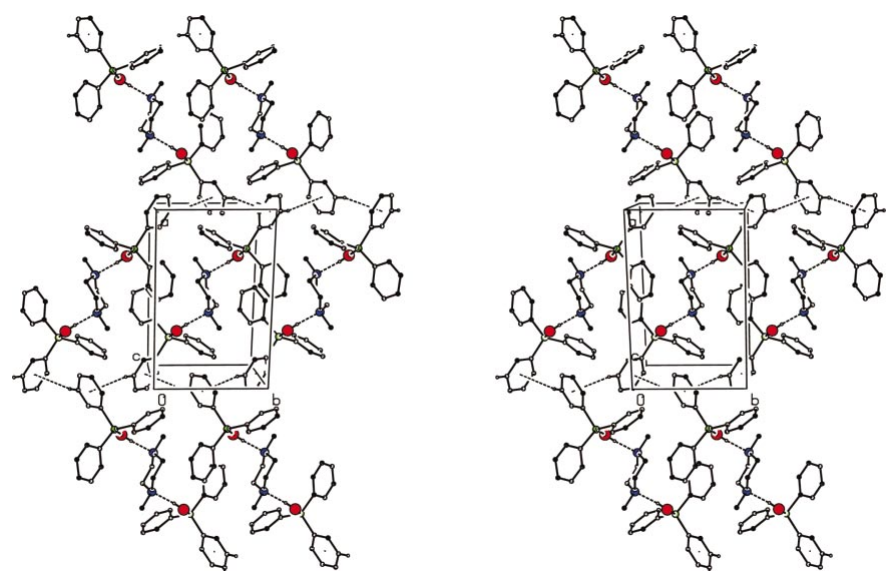

Figure 7

Stereoview of part of the crystal structure of (III) showing the formation of a $(10 \overline{2})$ sheet. For the sake of clarity the $\mathrm{H}$ atoms bonded to $\mathrm{C}$ atoms, but not involved in the hydrogen-bond motif shown, are omitted.

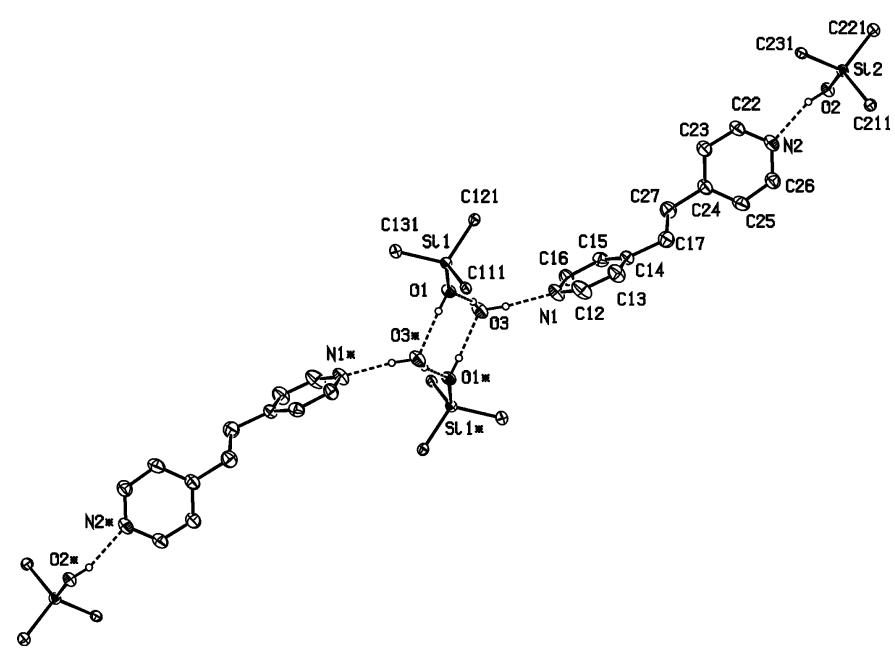

\section{Figure 8}

The eight-component aggregate in (IV) showing the atom-labelling scheme; phenyl $\mathrm{C}$ atoms are omitted except for those bonded to $\mathrm{Si}$. Displacement ellipsoids are drawn at the $30 \%$ probability level and the atoms marked with an asterisk (*) are at the equivalent position $(1-x, 1-y, 1-z)$. Only the $\mathrm{H}$ atoms involved in hydrogen bonding are shown. the eight-molecule aggregate centred at $\left(\frac{1}{2}, \frac{1}{2}, \frac{1}{2}\right)$. There is just one such aggregate per unit cell, but as the overall length of the aggregate exceeds $30 \AA$, portions of each aggregate occupy parts of several cells.

An extensive series of $\mathrm{C}-\mathrm{H} \cdots \pi($ arene) hydrogen bonds (Table 3) links the eight-component aggregates into a continuous three-dimensional framework and the formation of this framework can most readily be analysed in terms of a number of individual one-dimensional substructures. In the simplest of these, the $\mathrm{C} 115$ atom in the internal triphenylsilanol molecule at $(x, y, z)$, which lies in the eight-component aggregate centred at $\left(\frac{1}{2}, \frac{1}{2}, \frac{1}{2}\right)$, acts as a hydrogen-bond donor to the aryl ring C131-C136 of the corresponding silanol molecule at $(1-x,-y, 1-z)$, which itself lies in the aggregate centred at $\left(\cdots,-\frac{1}{2}, \frac{1}{2}\right)$. Propagation of this interaction by translation and inversion then generates a chain containing two types of ring running parallel to the [010] direction, which is built from just the internal silanol molecules and the water molecules (Fig. 9). In a somewhat similar motif, the $\mathrm{C} 235$ atom at $(x, y, z)$ acts as a hydrogen-bond donor to the ring $\mathrm{C} 211-\mathrm{C} 216$ at $(4-x,-y, 2-z)$, which lies in the aggregate centred at $\left(\frac{7}{2},-\frac{1}{2}\right.$, $\left.\frac{3}{2}\right)$, thereby generating a second chain of rings, thus time running parallel to the [3ī1] direction.

There are two one-dimensional substructures which each involve two $\mathrm{C}-\mathrm{H} \cdots \pi$ (arene) hydrogen bonds. In the first of these two, the $\mathrm{C} 16$ and $\mathrm{C} 224$ atoms at $(x, y, z)$ act as hydrogenbond donors, respectively, to rings $\mathrm{C} 221-\mathrm{C} 226$ at $(3-x, 1-y, 2-z)$ and $\mathrm{C} 111-\mathrm{C} 116$ at $(2+x, y, 1+z)$, which both lie in the aggregate centred at $\left(\frac{5}{2}, \frac{1}{2}, \frac{3}{2}\right) ;$ propagation of these hydrogen bonds then leads to a complex chain of rings running parallel to the [201] direction (Fig. 10). In the second
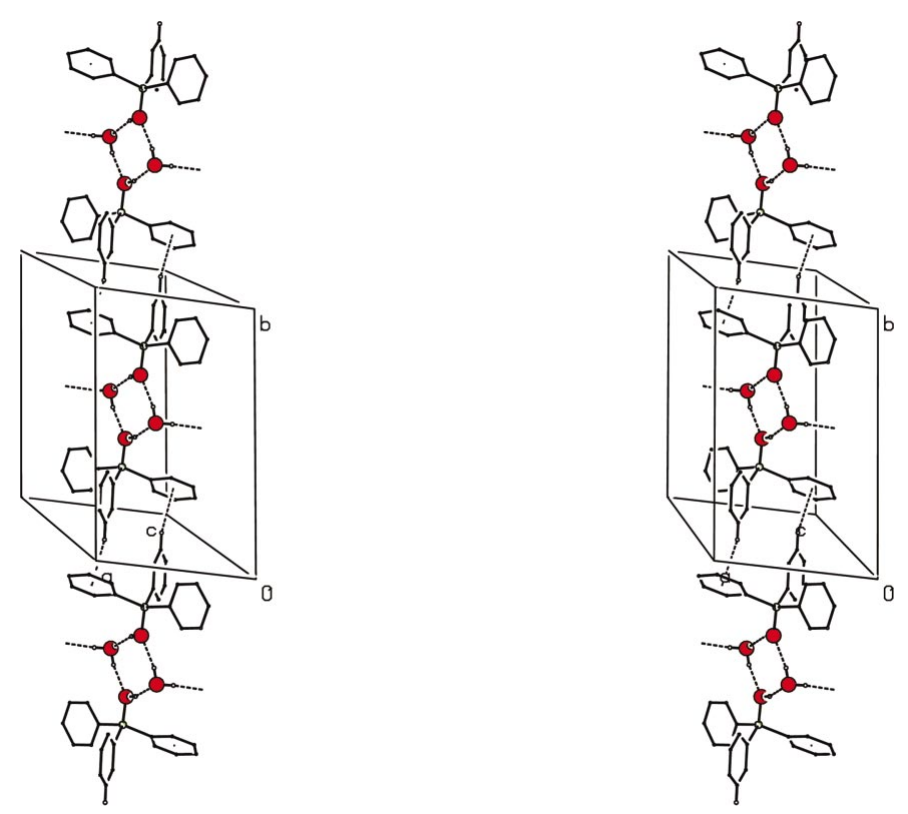

Figure 9

Stereoview of part of the crystal structure of (IV) showing the formation of a chain of rings along [010]. For the sake of clarity the $\mathrm{H}$ atoms bonded to $\mathrm{C}$ atoms, but not involved in the hydrogen-bond motif shown, are omitted. 
of these two substructures, the $\mathrm{C} 23$ and $\mathrm{C} 214$ atoms at $(x, y, z)$ act as donors, respectively, to the rings C211-C216 at $(-1+x, y, z)$ and to $\mathrm{C} 121-\mathrm{C} 126$ at $(2+x, y, z)$, which lie respectively in the aggregates centred at $\left(-\frac{1}{2}, \frac{1}{2}, \frac{1}{2}\right)$ and $\left(\frac{3}{2}, \frac{1}{2}, \frac{1}{2}\right)$. Propagation of these interactions generates a ladder-type substructure of some complexity running parallel to the [100] direction (Fig. 11).

The combination of chains running parallel to [100], [010], [201] and [311] is more than sufficient to link all of the eightmolecule aggregates into a single framework.

Hard hydrogen bonds generate a chain of rings: In our previous studies on adduct formation involving triphenylsilanol and 4,4'-bipyridyl, no 2:1 adduct was found: however, we have now isolated from methanol solution a dihydrated 2:1 adduct $\left(\mathrm{Ph}_{3} \mathrm{SiOH}\right)_{2} \cdot \mathrm{C}_{10} \mathrm{H}_{8} \mathrm{~N}_{2} \cdot\left(\mathrm{H}_{2} \mathrm{O}\right)_{2}(\mathrm{~V})$. All five independent molecular components in $(\mathrm{V})$ lie in general positions in the space group $P \overline{1}$ (Fig. 12). There are thus six independent $\mathrm{O}_{-}$ $\mathrm{H}$ bonds available for hydrogen-bond formation, so that there are six independent hard hydrogen bonds within the structure, four of the $\mathrm{O}-\mathrm{H} \cdots \mathrm{O}$ type and two of the $\mathrm{O}-\mathrm{H} \cdots \mathrm{N}$ type; together these hard hydrogen bonds generate a one-dimensional substructure which combines simplicity and elegance.

Within the selected asymmetric unit, the two triphenylsilanol atoms $\mathrm{O} 1$ and $\mathrm{O} 2$ act as hydrogen-bond donors to water atoms $\mathrm{O} 11$ and $\mathrm{O} 21$, respectively, and these water atoms in turn act as donors, respectively, to the N1 and N2 atoms in the bipyridyl unit. There are thus two $\mathrm{O}-\mathrm{H}$ bonds available to further link these five-molecule aggregates. The water atom $\mathrm{O} 11$ at $(x, y, z)$ acts as a hydrogen-bond donor, via $\mathrm{H} 11 B$, to the silanol atom $\mathrm{O} 1$ at $(3-x,-y, 1-z)$, thus forming a centrosymmetric $R_{4}^{4}(8)$ ring centred at $\left(\frac{3}{2} 0, \frac{1}{2}\right)$; in an entirely
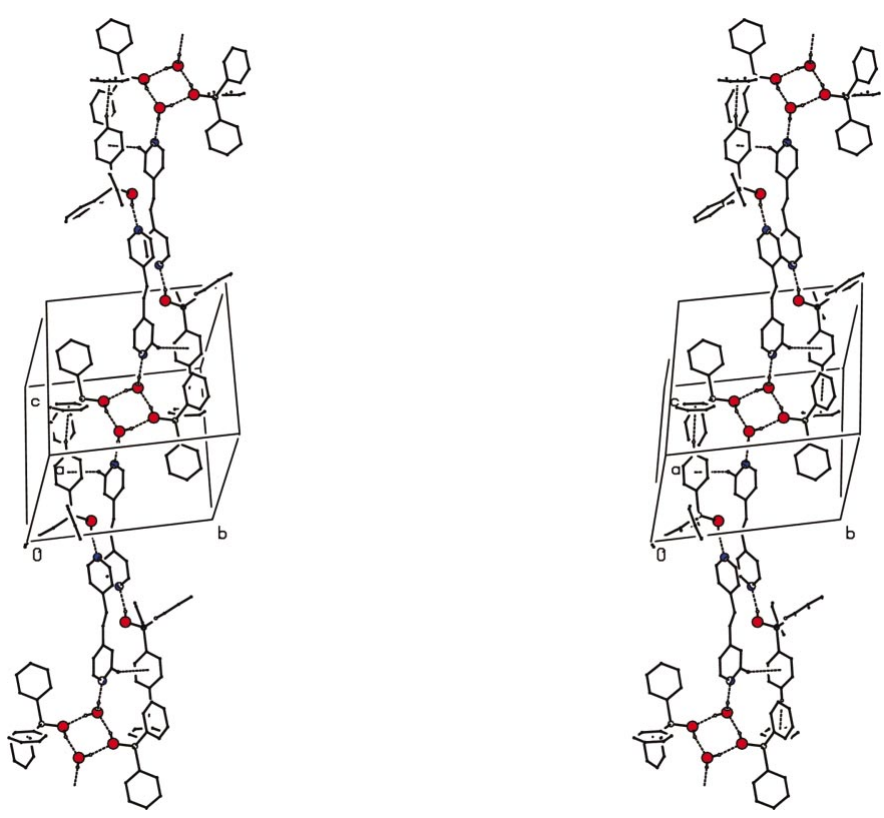

Figure 10

Part of the crystal structure of (IV), showing the formation of a chain of rings along [201]. For the sake of clarity the $\mathrm{H}$ atoms bonded to $\mathrm{C}$ atoms, but not involved in the hydrogen-bond motif shown, are omitted. similar manner, the water $\mathrm{O} 21$ at $(x, y, z)$ acts as donor, via $\mathrm{H} 21 B$, to the silanol atom $\mathrm{O} 2$ at $(-x,-y,-z)$, producing a second $R_{4}^{4}(8)$ ring, this time centred at $(0,0,0)$. Propagation of these motifs by inversion thus generates a $C_{8}^{8}(30)\left[R_{4}^{4}(8)\right]\left[R_{4}^{4}(8)\right]$ chain of rings running parallel to the [301] direction (Fig. 13).

There are four significant $\mathrm{C}-\mathrm{H} \cdots \pi$ (arene) hydrogen bonds in the structure of (V) (Table 3 ), all of which involve the phenyl groups only with no participation of the 4,4'-bipyridyl unit, and these link the [301] chains into a continuous threedimensional framework. It is convenient to consider the effects of these interactions in pairs.

The phenyl atom $\mathrm{C} 114$ in the aggregate at $(x, y, z)$ acts as a hydrogen-bond donor to the ring C221-C226 in the aggregate at $(2-x,-y,-z)$, thus forming a centrosymmetric ring motif centred at $(1,0,0)$; in combination with the $R_{4}^{4}(8)$ ring centred at $(0,0,0)$ this interaction generates a chain of rings running parallel to the [100] direction. In addition, the phenyl C124 atom at $(x, y, z)$ acts as a donor to the ring $\mathrm{C} 211-\mathrm{C} 216$ at $(2-x,-y, 1-z)$, forming another centrosymmetric ring motif, this time centred at $(1,0, \cdots)$; in combination with the $R_{4}^{4}(8)$ ring centred at $\left(\frac{3}{2}, 0, \frac{1}{2}\right)$, the second soft hydrogen bond generates another chain of rings running parallel to [100].

Similarly, the phenyl $\mathrm{C} 135$ and $\mathrm{C} 215$ atoms at $(x, y, z)$ act as hydrogen-bond donors, respectively, to the rings C111-C116 at $(3-x,-1-y, 1-z)$ and $\mathrm{C} 231-\mathrm{C} 236$ at $(-x, 1-y,-z)$, thus forming two further centrosymmetric ring motifs, centred at $\left(\frac{3}{2}\right.$, $\left.-\frac{1}{2}, \frac{1}{2}\right)$ and $\left(0, \frac{1}{2}, 0\right)$. In combination with the $R_{4}^{4}(8)$ rings centred at $\left(\frac{3}{2} 0, \frac{1}{2}\right)$ and $(0,0,0)$, respectively, the two motifs generate two further chains of rings, both running parallel to the [010] direction (Fig. 14). Each of the independent [010] chains in (V) thus has an overall architecture very similar to that of the unique [010] chain in (IV) (Fig. 9).

The combination of the [301] chains generated by hard hydrogen bonds with the [100] and [010] chains involving both
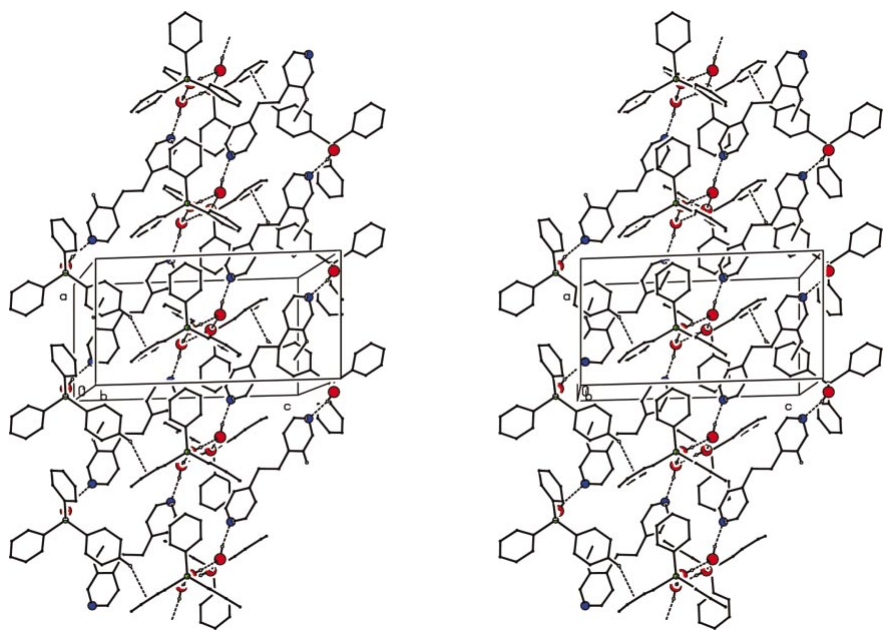

Figure 11

Part of the crystal structure of (IV) showing the formation of a molecular ladder along [100]. For the sake of clarity the $\mathrm{H}$ atoms bonded to $\mathrm{C}$ atoms, but not involved in the hydrogen-bond motif shown, are omitted. 


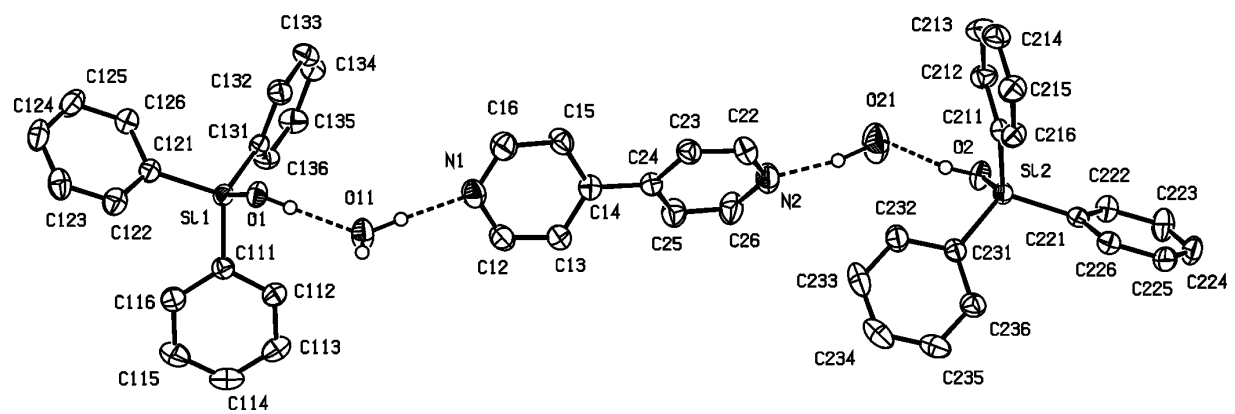

Figure 12

The independent molecular components in (V), showing the atom-labelling scheme. Displacement ellipsoids are drawn at the $30 \%$ probability level.

hard and soft hydrogen bonds is sufficient to generate a continuous three-dimensional framework.

\section{Concluding discussion}

In (I) and (II) the hard hydrogen bonds generate fivecomponent aggregates in which an inner pair of triphenylsi-

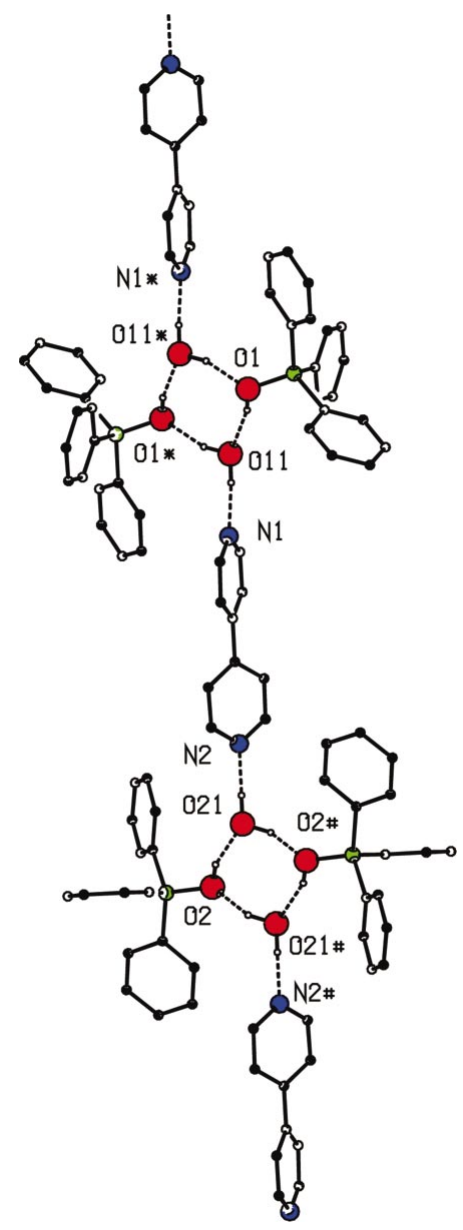

Figure 13

Part of the crystal structure of (V) showing the formation of a [301] chain generated by the hard hydrogen bonds. For the sake of clarity the unitcell box is omitted. The atoms marked with an asterisk $(*)$ or a hash (\#) are at the symmetry positions $(3-x,-y, 1-z)$ and $(-x,-y,-z)$, respectively. lanol molecules are hydrogen bonded to the central double acceptor, with an outer pair of triphenylsilanol molecules linked to the inner pair by means of $\mathrm{O}-\mathrm{H} \cdots \mathrm{O}$ hydrogen bonds. Entirely similar aggregates are found in the 4:1 adduct $\left(\mathrm{Ph}_{3} \mathrm{SiOH}\right)_{4} \cdot \mathrm{C}_{4} \mathrm{H}_{8} \mathrm{O}_{2}$ formed with 1,4-dioxan (Bourne et al., 1991; Bowes et al., 2002) and in all three polymorphs of the 4:1 adduct $\left(\mathrm{Ph}_{3} \mathrm{SiOH}\right)_{4} \cdot \mathrm{C}_{10} \mathrm{H}_{8} \mathrm{~N}_{2}$ formed with 4,4'-bipyridyl (Bowes et al., 2003). Moreover, (II) crystallizes in the space group $P \overline{1}$ with $Z^{\prime}=0.5$, as do the 1,4-dioxan adduct and the simplest of the 4,4'-bipyridyl adducts. Compound (I), on the other hand, crystallizes in the space group $P \overline{1}$ with $Z^{\prime}=2$, while the other two polymorphs of the 4,4'-bipyridyl adduct, both of which crystallize in the space group $P \overline{1}$, have $Z^{\prime}$ values of $2 \times 0.5=1$ and $(4 \times 0.5)+2=4$, respectively. No example has yet been observed of a $4: 1$ adduct in which a single five-component aggregate, of the general type exemplified by (I) and (II), lies in a general position.

At the start of this work, we had expected that 2:1 adducts of triphenylsilanol with diamines would represent the dominant stoichiometry, with hard hydrogen bonds giving rise to three-component aggregates: in the event, this has proved not to be so. Such an adduct is found with $N, N^{\prime}$-dimethylpiperazine (III), but the only 2:1 adduct so far observed with $4,4^{\prime}$ bipyridyl is the hydrated compound $(\mathrm{V})$, where the $R_{4}^{4}(8)$ rings are reminiscent of those in tetrameric triphenylsilanol itself. Similarly, with 1,2-bis(4-pyridyl)ethane, while the adduct (IV) does indeed contain a 2:1 ratio of triphenylsilanol to diamine molecules, this is also a hydrate and again, as in (V), there is a $R_{4}^{4}(8)$ ring present, analogous to those in $\left(\mathrm{Ph}_{3} \mathrm{SiOH}\right)_{4}$. In addition, we may note here the formation of a 2:1 adduct $\left(\mathrm{Ph}_{3} \mathrm{SiOH}\right)_{2} \cdot \mathrm{C}_{2} \mathrm{H}_{6} \mathrm{OS}$ formed with dimethylsulfoxide, in which a three-component aggregate lies across a twofold rotation axis, with the sulfoxide $\mathrm{O}$ atom acting as a double acceptor of $\mathrm{O}-\mathrm{H} \cdots \mathrm{O}$ hydrogen bonds (Bowes et al., 2002). However, the failure of triphenylsilanol to form crystalline adducts with piperazine and hexamethylenetetramine is unexpected.

Likewise, having characterized a number of adducts of triphenylsilanol and various diamines, we had initially expected that an analogous series of adducts would readily be formed with triphenylmethanol, $\mathrm{Ph}_{3} \mathrm{COH}$. Our reasoning here was based on the fact that whereas in the cyclic tetramer of triphenylsilanol there is one fully ordered $\mathrm{O}-\mathrm{H} \cdots \mathrm{O}$ hydrogen bond per $\mathrm{O} \cdots \mathrm{O}$ edge in the $R_{4}^{4}(8)$ ring (Bowes et al., $2002)$, in the tetrahedral tetramer of triphenylmethanol (Ferguson et al., 1992), there are only four hydroxyl $\mathrm{H}$ atoms distributed over the six $\mathrm{O} \cdots \mathrm{O}$ edges of the tetrahedron. These $\mathrm{H}$ atoms are, in fact, mobile over a number of sites at ambient temperature (Aliev et al., 1998), and neutron diffraction at $100 \mathrm{~K}$ was required to locate these $\mathrm{H}$ sites unambiguously (Serrano-González et al., 1999). Accordingly, we had expected that disruption of the triphenylmethanol tetramer would be 


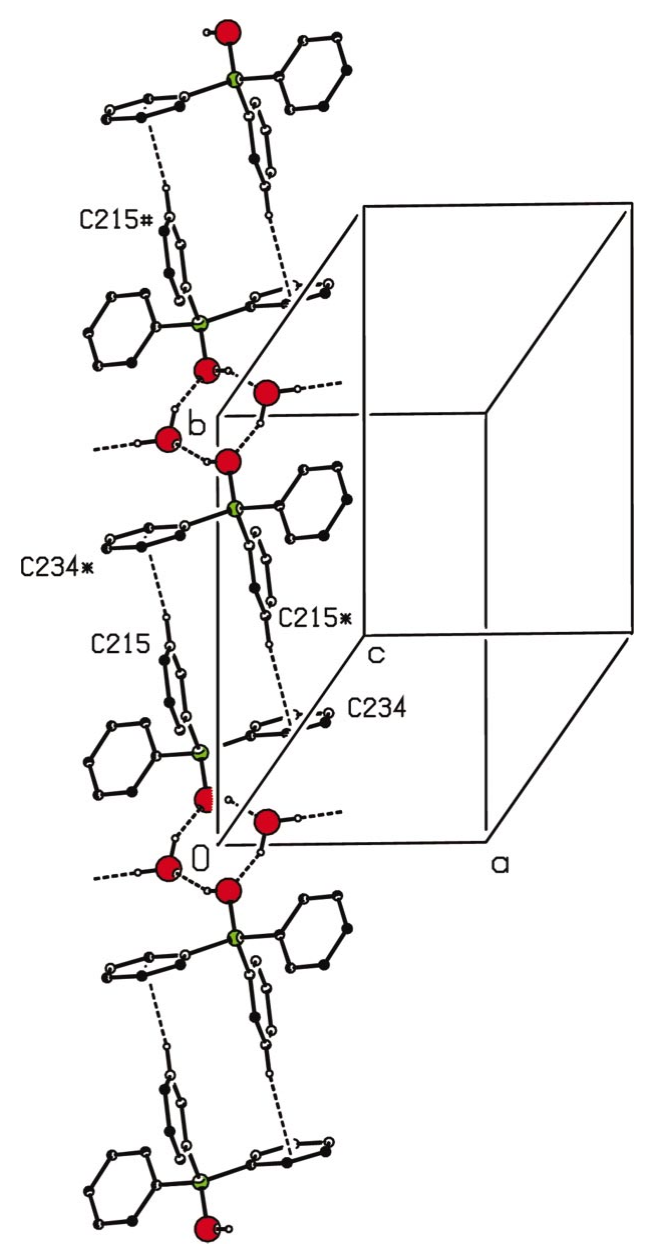

Figure 14

Part of the crystal structure of $(\mathrm{V})$ showing a representative example of a chain of rings generated by $\mathrm{O}-\mathrm{H} \cdots \mathrm{O}$ and $\mathrm{C}-\mathrm{H} \cdots \pi$ (arene) hydrogen bonds, in this case running parallel to [010]. The atoms marked with an asterisk $(*)$ or a hash $(\#)$ are at the symmetry positions $(-x, 1-y,-z)$ and $(x, 1+y, z)$, respectively.

achieved more readily than the disruption of the triphenylsilanol tetramer. Liberal application of hindsight suggests that an equally important consideration may be the intrinsic acidity of the hydroxyl groups in the two compounds $\mathrm{Ph}_{3} M \mathrm{OH}(M=$ $\mathrm{C}$ or $\mathrm{Si}$ ), where it is generally the case that silanols are more acidic than the corresponding carbinols (Eaborn, 1960; Sommer, 1965)

X-ray data were collected at the University of Toronto using a Nonius Kappa-CCD diffractometer purchased with funds from NSERC Canada.

\section{References}

Aliev, A., MacLean, E. J., Harris, K. D. M., Kariuki, B. M. \& Glidewell, C. (1998). J. Phys. Chem. B, 102, 2165-2175.

Batten, S. R. \& Robson, R. (1998). Angew. Chem. Int. Ed. 37, 14601494.

Bourne, S. A., Johnson, L., Marais, C., Nassimbeni, L. R., Weber, E., Skobridis, K. \& Toda, F. (1991). J. Chem. Soc. Perkin Trans. 2, pp. 1707-1713.

Bowes, K. F., Ferguson, G., Lough, A. J. \& Glidewell, C. (2003). Acta Cryst. B59, 277-287.

Bowes, K. F., Glidewell, C. \& Low, J. N. (2002). Acta Cryst. C58, o409o415.

Braga, D., Grepioni, F., Birdha, K., Pedireddi, V. R. \& Desiraju, G. R. (1995). J. Am. Chem. Soc. 117, 3156-3166.

Desiraju, G. R. \& Steiner, T. (1999). The Weak Hydrogen Bond, pp. 86-89. Oxford University Press.

Eaborn, C. (1960). Organosilicon Compounds. London: Butterworth and Co.

Farrugia, L. (1999). J. Appl. Cryst. 32, 837.

Ferguson, G. (1999). PRPKAPPA. University of Guelph, Canada.

Ferguson, G., Gallagher, J. F., Glidewell, C., Low, J. N. \& Scrimgeour, S. N. (1992). Acta Cryst. C48, 1272-1275.

Nonius (1997). Kappa-CCD Server Software. Windows 3.11 Version. Nonius BV, Delft, The Netherlands.

Otwinowski, Z. \& Minor, W. (1997). Methods Enzymol. 276, 307-326.

Serrano-González, H., Harris, K. D. M., Wilson, C. C., Aliev, A. E., Kitchin, S. J., Kariuki, B. M., Bach-Vergés, M., Glidewell, C., MacLean, E. J. \& Kagunya, W. W. (1999). J. Phys. Chem. B, 103, 6215-6223.

Sheldrick, G. M. (1997). SHELXS97 and SHELXL97. University of Göttingen, Germany.

Sommer, L. H. (1965). Stereochemistry, Mechanism and Silicon. New York: McGraw-Hill.

Spek, A. L. (2003). J. Appl. Cryst. 36, 7-13.

Wilson, A. J. C. (1976). Acta Cryst. A32, 994-996. 